NBER WORKING PAPER SERIES

\title{
POPULATION GROWTH, TECHNOLOGICAL ADOPTION AND ECONOMIC OUTCOMES: A THEORY OF CROSS-COUNTRY DIFFERENCES FOR THE INFORMATION ERA
}

\author{
Paul Beaudry \\ David A. Green \\ Working Paper 8149 \\ http://www.nber.org/papers/w8149 \\ NATIONAL BUREAU OF ECONOMIC RESEARCH \\ 1050 Massachusetts Avenue \\ Cambridge, MA 02138 \\ March 2001
}

This paper is part of our research program aimed at understanding cross-country differences in labor market outcomes over the last quarter of a century. We want to thank Ashok Kotwal, Gilles St-Paul and participants at seminars on our previous work for comments which have motivated us to write the current paper. The views expressed herein are those of the authors and not necessarily those of the National Bureau of Economic Research.

C) 2001 by Paul Beaudry and David A. Green. All rights reserved. Short sections of text, not to exceed two paragraphs, may be quoted without explicit permission provided that full credit, including (C notice, is given to the source. 
Population Growth, Technological Adoption and Economic Outcomes: A Theory of Cross-Country Differences for the Information Era

Paul Beaudry and David A. Green

NBER Working Paper No. 8149

March 2001

JEL No. J0, O3

\begin{abstract}
The object of this paper is to show how population growth, through its interaction with recent technological and organizational developments, can account for many of the cross-country differences in economic outcome observed among industrialized countries over the last 20 years. In particular, our model illustrates how a large decrease in the price of information technology can create a comparative advantage for high population growth economies to jump ahead in the adoption of computer- and skill-intensive models of production as a means to exploiting their relative abundance of human capital versus physical capital. The predictions of the model are that, over the span of the information revolution, industrial countries with higher population growth rates will experience a more pronounced adoption of new technology, a better performance in terms of increased employment rates, a poorer performance in terms of wage growth for less skilled workers, a larger increase in the service sector and a larger increase in the returns to education. We provide preliminary evidence in suport of the theory based on a comparative study of observed developments in the US, UK and Germany since the mid-seventies, complemented by an examination of broad wage and employment changes for 18 OECD countries over the same period.
\end{abstract}

Paul Beaudry

Department of Economics

University of British Columbia

997-1873 East Mall

Vancouver, B.C.

Canada V6T $1 Z 1$

and NBER

beaudry@econ.ubc.ca
David Green

Department of Economics

University of British Columbia

997-1873 East Mall

Vancouver, B.C.

Canada V6T 1Z1 


\section{Introduction}

Over the last twenty years, economic performance and labour market outcomes have differed substantially across industrialized countries (see for example Gottschalk and Smeeding (1997)). In particular, the labour market in the US has been characterized by a large increase in the employment rate, a poor wage performance for low skill workers, an increase in the returns to education and a fast expansion of the service sector . In contrast, continental Europe has witnessed low employment growth, no substantial change in the return to education, a decent performance in terms of wages for low educated workers and a slower expansion of the service sector. One obvious candidate explanation for these differences is institutional, that is, countries with more rigid institutions have adjusted to the introduction of new skill-biased technologies (like the spread of the computer) by adjusting quantities of employment instead of modifying the wage structure. However, as pointed out by, among others, Card, Kramarz, Lemieux (1999) and Krueger and Pischke (1997), a closer look at the data is not very supportive of an exclusively institutional explanation. ${ }^{1}$ Hence, this leaves open the question of why labour market outcomes and economic performance have differed so substantially between industrialized countries, and particularly between North America and Europe, over the last twenty years. Our goal in this paper is to present an alternative explanation for the observed cross-country differentials in labour market outcomes built on the interaction between two driving forces: population growth and the dramatic declines in the costs of using information technologies.

Our approach in this paper builds on our earlier work in Beaudry and Green (2000). In that paper, we showed how differences in wage changes between Germany and the US can be traced back to a differential growth in factors and especially

\footnotetext{
${ }^{1}$ The standard institutional explanation suggests that, in countries like Germany and France, the effects of skill-biased technical change should manifest itself through particularly large reductions in employment rates of low versus high skilled workers. However, as shown by Card, Kramarz and Lemieux (1999) and Krueger and Pischke (1997), this does not appear to have been the case.
} 
differences in the ratio of human to physical capital use. An important element of our analysis was to showed how wage and factor movements in these countries supported the view that technological adoption is an endogenous phenomenon which responds to profit incentives. In particular, our estimates indicated that firms in both these countries have been choosing between two broad classes of methods of production: where one of these methods of production is skilled biased and capital efficient relative to the other. Moreover, we found that the differential use of human versus physical capital can explain, through its effect on technological adoption, the differences in wage change patterns between these countries. The key question left unanswered in Beaudry and Green(2000) was why Germany and the US have differed so markedly in their accumulation paths for human versus physical capital. In this sense, our previous analysis was partial equilibrium in nature. In this paper, we build on insights from our previous work in order to propose a general equilibrium answer to the question of why labour market outcomes have differed so substantially across industrial countries over the last 20 to 25 year. The main elements of our answer reside in the effect of different rates of population growth on speed of technological adoption in conjunction with a massive decline in the cost of computer based capital.

The theoretical exercise we conduct to demonstrate our argument is as follows. We consider a set of economies at the dawn of the information revolution, that is, at a point in time after the introduction of computers but before the massive decrease in its price which led to its huge diffusion. We ask how differences in population growth affect economic outcomes in this pre-information-revolution environment. We then allow the cost associated with information processing to decrease substantially and we reexamine how differences in population growth affect labour market outcomes after such a change. Our main result is that, if the reduction in the cost of information or computer capital is sufficiently large, the effects of population growth on economic outcomes will change radically over the period. In particular, assuming human capital and new information technologies are complementary, we show why countries with higher population growth will experience - over the span of such an information 
revolution - a poorer performance in terms of wages for low skilled workers, a better performance in terms of increased employment rates, a larger increase in the service sector and a larger increase in the returns to education. Moreover, the countries with higher population growth will appear more dynamic over this period as they adopt new modes of production to a greater extent and tend to invest more in computing based capital.

The model we develop shares many features with those presented in the recent literature. For example, we adopt the consensus view that new methods of production are biased in favour of both capital and skilled labour (which is a version of the capital-skill complementarity assumption), and we focus on the adjustment induced by a fall in the relative price of information technology. The main new element we bring to the discussion is our emphasis on the importance of the ratio of human capital versus physical capital in understanding technological adoption and its relationship with population growth. There are two main components to the mechanism at work in our model. The first component involves the effects of population growth on a country's relative abundance (or scarcity) of human versus physical capital. In the spirit of Solow (1956), our model illustrates why countries with high rates of population growth are likely to exhibit a relatively high ratio of human capital to physical capital. The second element at work in our model involves the way a country's relative abundance (or scarcity) of human versus physical capital translates into the adoption of computer based means of production. In particular, if high population growth economies are economies with a higher ratio of human to physical capital, then they have a comparative advantage in the adoption of methods of production with similar factor intensities. However, before the information revolution, the most dominant characteristic of computer based methods of production is its high physical capital cost as opposed to its high human capital cost. Hence, in this phase, computer based methods of production are not particularly attractive to high population growth economies since the factor intensities pattern does not match with its comparative advantage. This leads high population economies to initially adopt computer 
based methods of production less than their low population growth counterparts. After the information revolution, the pattern reverses. The computer based method of production is now both human capital intensive and relatively inexpensive in terms of physical capital cost, i.e., it matches the relative factor supplies in the high population growth economies very well. As a result, the high population growth economies will move from being laggards in adoption of computer based methods of production to being aggressive leaders. Based on these results, we argue that differential speeds of technological adoption, driven by underlying differences in population growth, can account for many of the differences in economic performance observed across countries over the last quarter of a century. In particular, a greater shift toward the new technology in high population growth economies explains the greater observed increase in the returns to education and the poorer wage performance of low skilled workers in these economies. Moreover, we argue that this effects have been amplified by the endogenous response of labour supply to changes in the wage structure, which tends to further increase the ratio of human to physical capital in high population growth economies.

The remaining sections of the papers are structured as follows. In Section 2, we present a tractable dynamic general equilibrium model aimed at highlighting how population growth affects economic outcomes over a period in which there is a massive decrease in the cost of computer based capital. The main elements included in the model are that (1) households make saving decisions, education decisions and labour supply decisions, and (2) firms choose inputs and the method of production most appropriate to the supplied input. In particular, firms have a choice between two techniques of production; one which uses intensively computer-based capital and human capital, while the other uses more traditional capital and is less skill biased. In Section 3, we derive the effects of population growth on the steady state of this economy under two scenarios. In the first case, we assume that the cost of computer-based capital is high and hence the capital costs associated with adopting the skill-and-computer intensive technology is high. This is what we refer to as the 
pre-information revolution period. In the second case, we allow the cost of computer based capital to fall and we compare how this affects the performance of a high population growth economy relative to a lower population growth economy. The results of this analysis are summarized in Propositions 1 and 2 in Section 3.3. In Section 4, we discuss the mechanisms driving our results in hope of elucidating the generality of our argument. We also discuss how our results relate to the literature, and especially how they relate to the framework used by Krusell \& Al. (2000). In Section 4 we present some empirical evidence in support of our hypothesis. In particular, we present a comparative study of differences in economic performance, and its relation to population growth, in three major economies: the US, (former West) Germany and the UK. ${ }^{2}$ Our goal is to examine a wide range of economic outcomes and to clarify the unifying mechanism at play. We complement this case study approach with evidence on changes in wage and employment patterns in 18 industrialized countries. Finally, in Section 5 we offer some concluding comments.

\section{A Tractable General Equilibrium Model with population growth and endogenous technological choice}

Before presenting the details of the model, it is helpful to first overview the general strategy we adopt to address the issue at hand. The question we wish to address is complicated by its general equilibrium nature, by the fact that it involves the accumulation of different capital stocks and because it involves an endogenous choice of techniques of production. Obviously, we require substantial simplifications to proceed analytically. Moreover, the analysis is further complicated by the fact that we want to consider a non-marginal change in the economy, that is, the effects of a drastic reduction in the cost of computing and information processing. To address such a

\footnotetext{
${ }^{2}$ The paper and the empirical evidence we present is motivated by our previous work (Beaudry \& Green (1998),(2000)) which examines the relationships between wages and factor movements in the US and West Germany, and the US and Canada.
} 
rich issue, we proceed as follows. We first consider a situation where the efficiency of building computer based capital is low, say as indexed by $\theta_{0}$. We then derive the general equilibrium mapping which links the rate of population growth in the economy, denoted by $\eta$, to a set of economic variables of interest, which we can denote by $z_{0}$. Let this mapping be represented by the function $G(\cdot)$ where $z_{0}=G\left(\theta_{0}, \eta\right)$. We only examine the steady state mapping of our dynamic model since it is more tractable and it assures that all potential effects of factor accumulation are taken into account. We then consider the case where the efficiency of building computers is greatly improved as indexed by $\theta_{1}>>\theta_{0}$. The difference in economic outcomes over time, for an economy with rate of population growth $\eta$, is then given by $z_{1}-z_{0}=G\left(\theta_{1}, \eta\right)-G\left(\theta_{0}, \eta\right)$. The cross-country difference associated with difference in population growth, which is our object of interest, is therefore given by the following difference in derivatives:

$$
\frac{\partial\left(z_{1}-z_{0}\right)}{\partial \eta}=\frac{\partial G\left(\theta_{1}, \eta\right)}{\partial \eta}-\frac{\partial G\left(\theta_{0}, \eta\right)}{\partial \eta}
$$

This equation summarizes the focus of our paper. We are interested in examining how the computer revolution changed outcomes in the economy (the numerator on the left hand side of the equation), with our claim being that differences in population growth rates across countries (the denominator in the equation) are fundamental to understanding how the effects of the computer revolution were revealed in different economies. Note that our model will be able to unambiguously sign the effects of population growth on changes in economic variables (i.e, offer an explanation to cross-country differences) only if $\frac{\partial G\left(\theta_{1}, \eta\right)}{\partial \eta}$ is not the same $\operatorname{sign}$ as $\frac{\partial G\left(\theta_{0}, \eta\right)}{\partial \eta}$. Moreover, if this is the case, the sign of $\frac{\partial G\left(\theta_{1}, \eta\right)}{\partial \eta}$ will need to be the same as that of $\frac{\partial\left(z_{1}-z_{0}\right)}{\partial \eta}$. Hence, if for example we want to explain why, for a particular $z, \frac{\partial\left(z_{1}-z_{0}\right)}{\partial \eta}>0$, our approach requires us to explain both why $\frac{\partial G\left(\theta_{1}, \eta\right)}{\partial \eta}>0$ and why it is greater than $\frac{\partial G\left(\theta_{0}, \eta\right)}{\partial \eta}$. In other words, our modeling goal is to show why a reduction in cost of computer based capital can lead to a reversal of the general equilibrium mapping from population growth to a set of economic outcomes, and why in the resulting 
"new economy" the effects are in a particular direction. In this sense, our paper is essentially about showing how the information revolution has created a structural change in the functioning of the economy and that this structural change explains why countries with higher population growth have witnessed a particular pattern in economic outcomes in comparison to low population growth economies.

\subsection{The Model}

As is now well known ${ }^{3}$, the reduction in the cost of computer based capital has been enormous over the last quarter of a century and can reasonably be thought as a major force impacting on all industrialized economies. The issue that arises in this context is how best to model the opportunities created by such a change. Our choice is to follow the approach of Breshnahan et al. (1999), and view computer capital as an essential input into a new mode of production which is organized in order to exploit the joint use of human capital and information technology. To this end, we assume that firms have access to two constant returns to scale (CRS) production techniques (which produce the same final good): an older, traditional form of production, denoted $F^{O}(\cdot)$, which depends on traditional capital $(\mathrm{K})$, human capital $(\mathrm{H})$ and unskilled labour (L); and a modern production technique $\left(F^{M}(\cdot)\right)$ which depends only on computer based capital (IT) and on human capital. Hence, as in many recent papers (ex: Acemoglu (1999), Basu and Weil (1998), Beaudry \& Green (1998,2000), Caselli (1999), Zeira (1998)), we are considering an environment where the choice of technique of production is endogenous and is determined by firms seeking to maximize profits. In order to make the analysis as tractable as possible, we will assume that the two production techniques are as in Equations (1) and (2). ${ }^{4}$ However, as we show in the next section,

\footnotetext{
${ }^{3}$ See for example, Gordon (1990) and Jorgensen and Stiroh(1999).

${ }^{4}$ Throughout the paper we adopt a closed economy framework. Although this is an important simplifying assumption, we believe it is a more reasonable modeling strategy than adopting the alternative of a perfectly integrated financial market. In particular, Obsfeld \& Rogoff (2000) reiterate that implications implied by perfectly integrated international financial markets are not met in the data.
} 
our results are not restricted to these particular functional forms. Equations (1) and (2) are meant to capture two important properties. First, consistent with much of the literature, the more modern form of production is skill biased relative to the old technology, that is, the modern technology uses more skill per unit of output (since $\lambda<1$ ) and does not use unskilled labour. Secondly, IT capital is an input that complements human capital.

$$
\begin{gathered}
F^{O}(K, H, L)=\min \left[L^{.5} K^{.5}, H\right] \\
F^{M}(T, H)=\min [I T, \lambda H] \quad \lambda<1
\end{gathered}
$$

A firm's problem is to choose inputs and production techniques in order to maximize profits. Let us denote by $r_{k}, r_{I T}, r_{h}$ and $w$ respectively the rental price of traditional capital, computer based capital, human capital and unskilled labour. With this notation, the firms problem can be stated as:

$$
\max _{Y^{O}, Y^{M}, K, I T, H^{0}, H^{M}, L} Y^{O}+Y^{M}-\left(r_{k} K+r_{I T} I T+r_{H}\left(H_{1}+H_{2}\right)+w L\right)
$$

s.t.

$$
Y^{O}=F^{O}\left(K, H_{1}, L\right) \quad \text { and } \quad Y_{M}=F^{M}\left(I T, H_{2}\right), \quad Y^{O}, Y^{M} \geq 0
$$

Thus, we allow firms to use both techniques of production simultaneously. This formulation allows for firms to switch smoothly between technologies ${ }^{5}$ We now turn to the formulation of the household's problem.

In modelling the household, our objective is choose a specification which results in simple but plausible supply decisions. To this end, we assume that households live

\footnotetext{
${ }^{5}$ Alternatively, and without any implications for our results, we could have forced firms to adopt only one production technique and maintained continuity by aggregation across firms. Hence our model does not need to take a stand on whether technological adoption, and its implications, is a within or between firm phenomena. However, our focus on a one good world is in part motivate by the view that most aspects of recent technological changes appear to be a within goods or within industry phenomena.
} 
for one period and have a bequest motive which leads to savings. This setup has the attractive feature (compared to the standard OLG formulation) that it allows the aggregate savings rate to be independent of the functional distribution of income, which greatly simplifies the analysis.

In the one period of their life, each individual must decide on the amount of education to obtain, the amount of savings to bequeath, and the amount of time to supply to the market. However, for the sake of clarity, we begin by omitting the labour supply decision. The household's utility function is given by Equation (3), where $C_{t}$ denotes consumption, $\frac{B_{t+1}}{1+\eta}$ denotes the bequest per descendent and $\eta$ is the rate of population growth. ${ }^{6}$

$$
\frac{C_{t}^{1-\sigma}}{1-\sigma}+\beta \frac{\left(\frac{B_{t+1}}{1+\eta}\right)^{1-\sigma}}{1-\sigma}, \quad 0<\sigma \leq 1
$$

Given this formulation, the consumption decision leads to individuals consuming a fraction of their net incomes, with the fraction saved depending positively on the interest rate. Our results can be generalized to cases where $\sigma>1$, however this is omitted since it implies a savings rate which is a declining function of the interest rate. ${ }^{7}$ Each household is assumed to have one unit of labour time which they supply to the market and to have $1+\eta$ offspring. ${ }^{8}$

If an individual invests in education, his labour time is augmented to include units of human capital, which we denote by $h$. In this case, the labour earnings he will

\footnotetext{
${ }^{6}$ The case where $\sigma=1$ is meant to correspond to a $\log$ specification

${ }^{7}$ The one potentially controversial case ruled out by this specification is the situation where the supply of savings is perfectly elastic. In particular, our model rules out the long run behaviour implied by an infinitely lived agent model since such models implicitly imply an infinite long run supply of savings.

${ }^{8}$ Alternatively, we could have assumed that each dynasty has only one offspring and that there is a new set of dynasties, of relative size $\eta$, that enter the economy each period. This latter specification, which gives identical results, would be a means of capturing a process of population growth driven by immigration. We could also assume, without affecting results, that individuals care only about the size of bequests as opposed to the per-offspring size of bequests.
} 
receive from the market will be equal to $w_{t}+r_{h, t} h$, that is, the value of unskilled labour plus the value of his human capital. We assume that the cost of education associated with obtaining $h$ units of human capital (in terms of goods) is given for household $i$ by $Q_{i}(h)$, where $Q(0)=Q^{\prime}(0)=0, Q_{i}^{\prime}(h) \geq 0, Q_{i}^{\prime \prime}(h)>0$. We index the cost of education by $i$ since we will eventually want to allow for heterogeneity across households. With these additional elements, we can now state the household budget constraint as follows.

$$
C_{t}+\frac{B_{t+1}}{\left(1+r_{t+1}\right)}=w_{t}+r_{H, t} h_{t}-Q_{i}\left(h_{t}\right)+\frac{B_{t}}{1+\eta}
$$

In the above budget constraint, the individual receives as revenue a share: $\frac{1}{1+\eta}$ of the bequest $B_{t}$ left by the previous generation and labour earnings net of education costs equal to $w_{t}+r_{h, t} h-Q(h)$. The individual uses this revenue to spend on consumption and saves output at a return $\left(1+r_{t+1}\right)$ in order to leave a bequest $B_{t+1}$. Here, we have specified the cost of education in terms of output instead of as a time cost. This again is adopted to simplify the analysis. The household's optimal acquisition of human capital must satisfy Equation (5), where it can be seen that human capital investment will be a non-negative function of the price of human capital $r_{H, t}$. The optimal consumption decision is given by equation $(5 \mathrm{~B})$, where the savings rate is given by $\frac{1}{\beta^{\frac{-1}{\sigma}}\left(\frac{1+r_{t+1}}{1+\eta}\right)^{\frac{1-\sigma}{-\sigma}}+1}$. Note that when $\sigma=1$, the savings rate is a constant.

$$
\begin{gathered}
Q_{i}^{\prime}(h)=r_{H, t} \quad(5 A) \\
C_{t}=\frac{1}{\beta^{\frac{1}{\sigma}\left(\frac{1+r_{t+1}}{1+\eta}\right)^{\frac{1-\sigma}{\sigma}}+1}}\left(w_{t}+r_{H, t} h_{t}-Q_{i}(h)+\frac{B_{t}}{1+\eta}\right)
\end{gathered}
$$

In order to complete the model, we need to specify how saved output is transformed into physical capital. To this end, let there be a competitive intermediary which carries out the task of transforming a unit of saved output today into either one unit 
of traditional capital or $\theta_{t}$ units of computer based capital for the next period. Hence, $\theta$ represents the efficiency level by which a unit of output can be transformed into computer based capital. It is a non-marginal change in this variable that we will referred to as the information revolution. The constant return to scale nature of this transformation technology implies that the rate of return on savings must be equal to rates of return on both traditional and computer based capital. Assuming full depreciation of capital stocks across periods (again for simplicity), we therefore have the arbitrage conditions:

$$
1+r_{t}=r_{K, t}=\theta_{t} r_{I T, t}
$$

In the absence of heterogeneity across households (i.e., with $Q_{i}(h)$ independent of i) a Walrasian Equilibrium for this economy is a sequence of prices $\left\{w_{t}, r_{H, t}, r_{K, t}, r_{I T, t}, r_{t}\right\}$ and allocations $\left\{h_{t}, B_{t+1}, L_{t}, H_{t}, K_{t}, I T_{t}\right\}$ such that (i) given prices, $h_{t}$ and $B_{t+1}$ solves the consumers problem (i.e, maximizes (3) subject to (4)), (ii) given prices, $L_{t}, K_{t}, H_{t}$ and $I T_{t}$ solves the firm's problem, (iii) the arbitrage conditions given by (6) are satisfied, and (iv) markets clear, that is, $L_{t}=(1+\eta)^{t}, H_{t}=h_{t}(1+\eta)^{t}, \frac{B_{t}}{1+r_{t}}(1+\eta)^{t-1}=$ $K_{t}+\frac{I T_{t}}{\theta}$, where we have normalized the size of the initial population to 1 . We will focus only on steady state equilibria, that is, time invariant vectors of prices and constantly growing allocations (at growth rate $\eta$ ) which form a Walrasian Equilibrium for a given level $\theta$ of the computer efficiency index. Before looking at the properties of such an equilibrium, and especially the effects of changing $\eta$, we first examine how the model can be modified to incorporate both endogenous labour supply with heterogeneous households, and a service sector. We take this to be an important issue since the behaviour of employment rates and participation rates have evolved very differently between countries, as has the size of the service sector. 


\subsection{Introducing Variable Labour Supply Decisions and a Household Ser- vice Sectors}

We now want to extend the household's problem to incorporate two new decision variables, which are time supplied to the market, denoted $l_{t}$, and the amount of household related services purchased from the market, $s_{t}$. The tradeoff we envision involves the household fulfilling its needs in terms of a domestic good either by withdrawing time from market activity or by buying related services on the market. To this end, let us denote by $D\left(1-l_{t}, s_{t}\right)$ the household's production of domestic goods achieved when $1-l_{t}$ of time is devoted to household production and $s_{t}$ services are bought on the market (at price $p_{t}^{s}$ ). Furthermore, let us assume that the household's requirement in terms of domestic services is a fixed amount $\bar{d}$ and that, for simplicity, the function $D(\cdot)$ takes the following form $D\left(l_{t}, s_{t}\right)=D_{0}\left(1-l_{t}\right)^{\alpha}+s_{t}, \quad 0<\alpha<1$. The household's problem can therefore be stated as:

$$
\max _{c_{t}, B_{t+1}, h_{t}, l_{t}, s_{t}} \frac{c_{t}^{1-\sigma}}{1-\sigma}+\beta \frac{\left(\frac{B_{t+1}}{1+\eta}\right)^{1-\sigma}}{1-\sigma}
$$

s.t

$$
\begin{gathered}
D\left(1-l_{t}, s_{t}\right)=\bar{d} \\
c_{t}+\frac{B_{t+1}}{\left(1+r_{t+1}\right)}=\left(w_{t}+r_{H, t} h_{t}\right) l_{t}-Q_{i}\left(h_{t}\right)-p_{t}^{s} s_{t}+\frac{B_{t}}{(1+\eta)}
\end{gathered}
$$

The first order condition associated with the household's labour supply decision, which is $\alpha D_{o}\left(1-l_{t}\right)^{\alpha-1}=\frac{w_{t}+r_{H, t} h_{t}}{p_{t}^{a}}$, implies that the time spent in the market will be positively related to the ratio of the household's effective wage $\left(w+r_{H} h\right)$ and the price of household related services $\left(p^{s}\right)$. Hence, changes in relative prices affect labour supply decisions. In order to see this mechanism most clearly, let us introduce heterogeneity between households and eliminate the education decision by assuming that there is a measure $\pi$ of households which obtain no education and a measure $1-\pi$ with obtain education level $h_{2}$ (without loss, we can therefore disregard the 
cost of education in this case). Furthermore, let us assume that household services $s$ are produced in the market using a CRS to scale production function which produces one unit of services with one unit of unskilled labour. This will imply that the price of services is equal to the price of unskilled labour, $w_{t}$. In this case, which will be our case of reference when we refer to the case with endogenous labour supply ${ }^{9}$, the labour supply decision of the no-education household is not affected by changes in either $w_{t}$ or $r_{H, t}$ (since only the ratio of $w_{t}$ to $p_{t}^{s}$ enter the FOC, and this ratio is 1 ). However, the labour supply decision of the more educated household will be affected by changes in the wage structure. In particular, the educated household's labour supply is positively affected by an increase in the price of skill labour $r_{H, t}$ relative to the price of unskilled labour $w_{t}$. This ratio is generally referred to in the literature as the return to education, and we will adopt this convention, even though in terms of goods (which is the usual benchmark for most returns), the return to education is $r_{H, t} \cdot{ }^{10}$

A Walrasian Equilibrium for the economy with endogenous labour supply and two types of households, denote by $i=1$ or 2 , is a sequence of prices $\left\{w_{t}, r_{H, t}, r_{K, t}, r_{I T, t}, r_{t}, p_{t}^{s}\right\}$ and allocations $\left\{l_{1, t}, l_{2, t}, B_{1, t+1}, B_{2, t+1}, s_{1, t}, s_{2, t}, L_{t}, H_{t}, K_{t}, I T_{t}\right\}$ such that (i) given prices, $l_{i, t}, s_{i, t}$ and $B_{i, t+1}$ solves the consumers problem given $h=0$ for $i=1$ or $h=h_{2}$ for $i=2$, (ii) given prices, $L_{t}, K_{t}, H_{t}$ and $I T_{t}$ solves the firm's problem, (iii) the arbitrage condition given by $(6)$ is satisfied and $p_{t}^{s}=w_{t}$, and (iv) markets clear, that is, $L_{t}=(1+\eta)^{t}\left(\pi\left(l_{1, t}-s_{1, t}\right)+(1-\pi)\left(l_{2, t}-s_{2, t}\right)\right), H_{t}=(1-\pi) h_{2}(1+\eta)^{t},\left(\pi B_{1, t}+\right.$ $\left.(1-\pi) B_{2, t}\right)(1+\eta)^{t-1}=\left(K_{t}+\frac{I T_{t}}{\theta}\right)\left(1+r_{t}\right)$. We will again only focus on the steady state equilibrium, that is, the time invariant vector of prices and constantly growing allocations (growth rate $\eta$ ) which form a Walrasian Equilibrium for a given level $\theta$.

\footnotetext{
${ }^{9}$ Note that the more general cases with heterogeneity and simultaneous educations and labour supply decisions can be handled, but without any gain in terms of results or insight.

${ }^{10}$ We note this difference in vocabulary since it often leads to confusion. In particular, if a production function is convex, an increase in the use of human capital use will always imply a reduction in the return to education in terms of goods, but does not necessarily imply a reduction in the return to education in terms of the price of unskilled labour.
} 
Furthermore, for reasons we discuss later, we focus on the case where $\alpha$, which governs the elasticity of labour supply, is not too large. Note that if we were to assume that $\alpha=1$ (infinite elasticity), this would by assumption pin down the returns to education and hence defeat the purpose of the analysis.

\section{Equilibrium Analysis}

In this section, we will perform four comparative static exercises. In the first instance, we will examine the effects of population growth for the situation where computer based capital is relatively expensive, that is, where $\theta$ is low. In this state, the adoption of the new computer-and-skill intensive technology will be costly in terms of savings and hence will not be favoured by high population growth economies. We examine outcomes in the versions of the model in which: i) human capital accumulation is endogenous, and ii) when labour supply (and hence the size of the household service sector) is endogenous. We then examine how a large reduction in the cost of computer based capital modifies economic outcomes. Our main result is that, if the reduction in the cost of computer based capital is sufficiently large, the effects of population growth on the economy will change drastically and in a direction consistent with what is actually observed in terms of differences in economic outcomes between high and low population growth economies in recent times. The intuition for these results is based on the tendency for high population growth economies to have a relative high ratio of human to physical capital, leading them to favour technologies with similar factor intensities. Although the modern technology always uses human capital intensively, in the pre-information revolution when IT capital is very expensive, high population growth economies tend to produce using mainly the traditional technology since the physical capital costs associated with the modern technology are too high. However, when the computer revolution generates a dramatic decline in the cost of IT capital, it becomes particularly advantageous for high population growth economies 
to switch toward modern mode of production since the latter has both less expensive capital costs and make more use of human capital. Hence, high population growth economies will tend to leapfrog over low population growth economies in terms of their adoption of the new technology (and new mode of work organization) as a means of taking advantage of their comparative advantage in using modes of production with a high ratio of human versus physical capital. Thereby countries with high population growth will experience a more radical change in the structure of their economies as it transits through the information revolution. In this sense, our model suggests that the information revolution creates a structural change which is especially evident in high population growth countries.

\subsection{The Pre-Information-Revolution Era}

The adoption of the modern technology $F^{M}(I T, H)$, as specified in Equation (1), depends on the parameter $\lambda$ and on the cost of computer based capital which is parameterized as $\frac{1}{\theta}$. As we have previously indicated, we will assume throughout that this new technology is skill-biased in the sense that $\lambda<1$. This is consistent with much of the recent literature which emphasizes the skill-biased aspect of recent technologies, and it is consistent with Goldin \& Katz's (1998) longer term view suggesting that most techniques of production introduced in the 20th century were skilled biased. Moreover, we wish to assume that the technology is relevant in the sense that, at the prices that would prevail in the absence of this technology, it would be profitable to adopt the technology. This corresponds to the requirement that $\frac{r_{K}^{*}}{\theta_{0}}+\frac{r_{H}^{*}}{\lambda} \leq 1$, where $r_{K}^{*}$ and $r_{H}^{*}$ are the prices that prevail in the absence of the modern technology, and where $\theta_{0}$ denotes the value of $\theta$ in this initial era. Finally we also want to be consistent with Goldin \& Katz's evidence that new technologies, at least when they are first introduced, have predominantly been capital intensive as well as skill intensive. In effect, we will assume that the computer based technology was heavily capital intensive (in terms of dollars of capital cost per unit of produced output) when it 
was first introduced (ex: think of robotics), that is, we will assume that its relative capital intensity was initially more important than it skill intensity. The current emphasis on the importance of educated workers in production appears to us to be a phenomenon that has followed the massive decrease in the price of computer based capital as opposed to preceding it. To state the requirement formally, let $k^{*}$ denote the capital-output ratio in the traditional production method. Our main assumption about the Pre-Information-Revolution era is that the physical capital to human capital ratio in the new technology, which is $\frac{\lambda}{\theta_{0}}$ once properly normalized for the difference in types of capital, is greater than the corresponding ratio in the traditional technology, which is given by $\frac{1}{k^{*}}{ }^{11}$

We are now in a position to examine how different rates of population growth will affect economic outcomes, under the assumption that the efficiency index associated with building computer based capital is relatively low. However, before deriving the first set of results, it is worth emphasizing that we do not think that these preliminary results are of direct empirical relevance since they refer to levels of variables, which in reality are influenced by a whole set of country specific factors other than population growth. For example, countries may differ in their overall efficiency in production (as captured by something like overall TFP) and differences in education systems across countries may make level comparisons difficult. Nevertheless, by adopting a "before and after strategy" in our theoretical model, we can derive a set of predictions which are robust to both country fixed effects (e.g., levels of TFP, differently measured price indices) and to arbitrary but common time effects (e.g., trend growth in female labour supply, overall TFP growth). With this in mind, we now turn to deriving a

\footnotetext{
${ }^{11} \mathrm{It}$ is interesting to note that the working of the economy under this assumption will be consistent with most conventional views of the functioning of the economy. For example, in this pre-information revolution era, (1) an increase in capital accumulation due to increased saving is especially beneficial to highly skilled workers and (2) an increase in human capital due to greater investments in education will lead to a reduction in both the rental price of human capital as well as the returns to human capital in terms of the low skill wage. Hence, it is an assumption that corresponds to assuming that in this pre-information revolution phase, the economy behaved in a rather conventional manner. The important issue for us is to show how the simple reduction in the cost of computer based capital, starting from a rather conventional state, can in effect drastically change the behaviour of the economy.
} 
set of results without relating them to observations. We will wait until the end of this section, where we contrast the "before and after predictions" (in Propositions 1 and 2), before relating the theoretical results to empirical counterparts.

The first Lemma examines the effects of differences in population growth rates on a set of variables.

Lemma 1A: In the steady state of the economy with endogenous accumulation of human and physical capital, when $\theta=\theta_{0}$ (the pre-information revolution era), a higher population growth rate is associated with:

- A higher price of unskilled labour $\left(w_{1}\right)$

- A lower price of human capital $\left(r_{H}\right)$

- A lower return to education $\left(\frac{r_{H}}{w_{1}}\right)$.

- A lower level of output (per capita) produced using the modern mode of organization.

Proof: See Appendix A

The key mechanism underlying Lemma $1 \mathrm{~A}$ is one similar to that emphasized in the neo-classical growth model as developed by Solow (1956), that is, in a high population growth economy physical capital tends to be relatively scarce due to the constant need to use savings to equip new labour market entrants. However, this relative scarcity of physical capital is not in general transmitted proportionally to human capital since the latter responds more directly to the size of new cohorts. In particular, our model illustrates why high population growth economies are likely characterized by a relatively high ratio of human to physical capital. The second element to note is that in the pre-information revolution era, the capital cost associated with adopting the new technology is high relative to its cost in terms of human capital. Hence, in the 
economy with a higher population growth rate, where physical capital is the relatively expensive factor compared to human capital, the incentives are for firms to refrain from adopting the new technology aggressively since they do not have a comparative advantage in doing so. Given that the new technology is more widely adopted in low population growth economies and that it is skill biased, the price of human capital will tend to be higher in the low $\eta$ economies. Furthermore, the adoption of this new technology is to the detriment of low skilled workers as it reduces investment and available skill in traditional modes of production, which are both complementary to unskilled labour, implying a low price of unskilled labour in the low population growth economies. ${ }^{12}$ We now examine how the introduction of variable labour supply affects these results.

Lemma 1B: In the steady state of the economy with endogenous accumulation of physical capital and endogenous labour supply, if $\theta=\theta_{0}{ }^{13}$, a higher population growth rate is associated with the same effects as noted in Lemma $1 \mathrm{~A}$ plus:

- A lower employment rate.

- A lower per capita level of employment in the service sector.

Proof: See Appendix B

The intuition for Lemma 1B is as follows. Since the economy with the high rate of population growth does not tend to adopt the new technology aggressively in the pre-information revolution era, it tends to have a more equal wage structure. In turn, the more equal wage structure is a deterrent to market transactions in services

\footnotetext{
${ }^{12}$ Note that this process of reallocation of factors across different modes of production, and it implications, is akin to that presented by in Caselli (1999) and in Beaudry \& Green (1998,2000).

${ }^{13}$ This Lemma holds true for all values of $0 \leq \alpha<1$.
} 
between more and less educated household. Hence, the employment rate tends to be lower in the high population growth rate economies relative to the low growth rate economies, as does the size of the service sector. Note that the effect of allowing endogenous labour supply in this case is actually to dampen the direct effects induced by differences in population growth, that is, with endogenous labour supply decision countries with different rates of population growth will tend to have more similar outcomes than in the absence of an endogenous response of labour. The reason is that by reducing labour supply, the high population growth rate economies are actually reducing the relative scarcity of physical capital relative to human capital . It may therefore be the case that, in the pre-information revolution era, the endogenous response of labour causes the net effects of population growth on wages to be of small order. We will see that the opposite is true in the post-information revolution era, that is, the labour supply response tends to amplify the effects induced by population growth on the wage structure. This may explain why wage effects due to differences in population growth may have become apparent only more recently.

\subsection{The Post-Information Revolution Era}

We now examine how population growth affects economic outcomes when the cost of producing computer based capital is low. The following two Lemmas address this issue by examining the case where there has been a sufficiently large decrease in the cost of computer based capital.

Lemma 2A: There exists a $\theta^{*}>\theta_{0}$ such that, if $\theta \geq \theta^{*}$, in the steady state of the economy with endogenous accumulation of human and physical capital, a higher population growth rate is associated with:

- A lower price of unskilled labour $\left(w_{1}\right)$

- A lower price of human capital $\left(r_{h}\right)$ 
- A higher return to education $\left(\frac{r_{H}}{w_{1}}\right)$.

- A lower per capita level of output produced using the traditional mode of organization.

Proof: See Appendix A

The effect of a large enough reduction in the cost of computer based capital is to change the relative cost structure of the modern versus the more traditional mode of production. A sufficient increase in $\theta$ is therefore almost like inventing a new mode of production, that is, a technology that uses human capital intensively and is efficient in its use of physical capital. This particular pattern of factor intensities conforms well to that available in high population growth economies and hence they naturally move to adopt this new form of production. Since low growth economies do not exhibit the same factor ratios, they adopt it less aggressively. Again, greater adoption of the modern technology means less human and physical capital allocated to the traditional technology and, hence, a lower unskilled wage. Moreover, the decrease in the price of IT favors skilled workers and hence leads to an increase in the returns to education. 14

Lemma 2B: There exists a $\theta^{* *}>\theta_{0}$ such that in the steady state of the economy with endogenous accumulation of physical capital and endogenous labour supply, if $\theta \geq \theta^{* *}$ (the post-information revolution era) and if $\alpha$ is not too large ${ }^{15}$, a higher

\footnotetext{
${ }^{14}$ Given the work by Blanchard (1997), it would also be of interest to know the predictions of our model with respect to the income share of capital. Although this effect in not unambiguous in our model, we are able to show that, if the endogenous response of human capital is not too large, the low population growth economy with exhibit a higher income share of capital in the post-information revolution era.

${ }^{15}$ The more general statement is that there exists a $\alpha^{*}$ such that if $\alpha<\alpha^{*}$, then the statement given in Lemma $1 \mathrm{~B}$ is true, otherwise the opposite is true. We choose to focus only on the case where $\alpha<\alpha^{*}$ since the opposite case does not appear very relevant. In particular, in the case that $\alpha>\alpha^{*}$, a higher population growth is associated with a lower interest rate since the scarcity of capital associated with high population growth is more than offset by the endogenous response of labour supply. An easy way to visualize what is happening when $\alpha$ is sufficiently large is to note that the general equilibrium supply and demand curves for capital no longer cross in the standard fashion.
} 
population growth rate is associated with the same phenomena as noted in Lemma 2A plus:

- A higher employment rate.

- A high per capita level of employment in the service sector.

Proof: See Appendix B

The mechanisms at work in Lemma $2 \mathrm{~B}$ are the same as those behind the earlier results. In the post-information revolution era, the high population growth economy is adopting the modern technology aggressively thereby leading to a greater disparity in wages between low and high skilled individuals. This disparity in wages in turn favours greater market transactions in services between high and low skilled household. In

effect, households with high levels of human capital increase their labour supply and purchase a greater amount of services in the market. This leads to a higher rate of employment and a larger service sector. In addition, the effect of labour supply in this case is to amplify the effects stated in Lemma 2A. For example, as the more educated household offers more labour in the market this further favours the adoption of the modern form of technology since it is skilled biased. Capital will be shifted toward the modern technology, further increasing the capital scarcity in the traditional mode of production. With less capital applied to the traditional technology, low skilled wages drop and the role of low skilled workers as providers of services to the more educated households is expanded.

\subsection{The performance of high and low population growth rate economies over the span of the information revolution}

In this section we simply gather together the elements presented in Lemmas $1 \mathrm{~A}, 1 \mathrm{~B}, 2 \mathrm{~A}$ and $2 \mathrm{~B}$ in order to emphasize the predictions of our model in terms of changes in factor 
prices and production structure realized over the span of an information revolution. Recall, that it is the contents of Propositions 1 and 2 which we believe are empirically relevant since, due to the "before and after" nature of the exercise, only these predictions are robust to potentially omitted country fixed effects or other common time trends.

Proposition 1:In the economy with endogenous accumulation of both physical and human capital, if there is a sufficiently large reduction in the cost of IT capital (starting from $\theta=\theta_{0}$ ), then the higher an economy's rate of population growth rate

- The poorer the performance in terms of the price of unskilled labour.

- The greater the increase in the returns to education. ${ }^{16}$

- The greater the change towards using the modern mode of organization more intensively. ${ }^{17}$

Proof: These results follow directly from Lemma $1 \mathrm{~A}$ and Lemma $2 \mathrm{~A}$ and the logic presented at the beginning of Section 2

Proposition 2:In the economy with endogenous accumulation of physical capital, if there is a sufficiently large reduction in the cost of IT capital (starting from $\theta=\theta_{0}$ ) and if $\alpha$ is not too large, then a higher the rate of population growth implies the same effects as stated in proposition 1 plus it implies,

\footnotetext{
${ }^{16}$ Note that the effect of population growth on the change in the price of human capital, as opposed to the return, is ambiguous. Moreover, the model is consistent with countries having similar changes in educational attainment but large changes in the return to education.

${ }^{17}$ From Lemma $1 \mathrm{~A}$ and $2 \mathrm{~A}$, we know that a high population growth economy goes from having a relatively low level of activity in the modern technology to having a low level of activity in the traditional technology. It is in this sense that we can say that the high population growth economy exhibits a greater change towards using the modern mode of organization more intensively. If furthermore we assume that the elasticity of education supply is not too great $\left(Q^{\prime \prime}>>0\right.$ ), then over the course of the information revolution, it can be shown that the high population growth economy is actually characterized by a greater increase in the fraction of output produced using the modern form of organization.
} 
- a larger growth in per capita employment.

- a larger growth in per capita employment in the service sector.

Proof: These results follow directly from Lemma $1 \mathrm{~A}$ and Lemma $2 \mathrm{~A}$ and the logic presented at the beginning of Section 2

The general picture that emerges from Proposition 1 and 2 is one suggesting that the information revolution can affect economic outcomes across countries very differently simply because countries differ in their rates of population growth. In effect, these propositions suggest that high population growth economies may experience a transformation induced by the information revolution which, both in terms of the structure of wages and in terms of the structure of production and employment, is much greater is scope than that induced in low population growth economies. The intuition behind these propositions is the same as that discussed with the Lemmas. In our framework, the information revolution causes modern production processes (or modern form of work organization), which rely on computer based capital, from initially being processes which are relatively costly in terms of capital expenditures to processes which are inexpensive in terms of capital expenditures. ${ }^{18}$ Due to this change, countries with high population growth rates find it to their advantage to aggressively adopt the more modern form of production as a means of taking advantage of their relatively high ratio of human capital to physical capital. Thus, these countries move from being slow in implementing new computer based technologies (like robotics in the seventies), to being the leaders. The shift toward the modern technology implies a shift away from the traditional technology which harms the low skilled workers employed there. The low skilled workers then respond by exploiting new opportunities in the service sector. The more skilled workers in the high population growth economies recognize the gains associated with reducing their time

\footnotetext{
${ }^{18}$ In effect, these processes become ones where the major cost disadvantage is terms of human capital as opposed to physical capital.
} 
devoted to household services and instead supply more time to the market and buy more services. Both these latter effects play an amplifying role in the entire process, potentially causing small differences in population growth to generate large differences in wage profiles and employment patterns.

\section{Generalization and Related Literature}

Propositions 1 and 2 have been derived within the confines of a specific model with particular parametric assumptions. It is therefore natural to ask: (1) what are the general mechanisms driving these results and (2) are these mechanisms robust to the relaxation of of key assumptions. In order to an answer these questions, we begin by noting that there are essential four elements driving our results. The first relates to the mechanism by which population growth affects a country's accumulation of factors. The second relates to how the economy functions when the capital cost associated with the skill biased (modern) technology are relative high. The third relates to how the economy functions when the capital costs associated with the skill biased (modern) technology are relatively low. The fourth element relates to whether a sufficient reduction in the relative price of computer based capital (the type of capital used in the modern technology) will cause the economy to go from a situation where the modern technology has relatively high capital costs to one with relatively low capital costs (a condition that we make precise below). The mechanism by which population growth affects factor intensities in our model is similar to that in Solow (1956), and hence is quite conventional. As we discuss below, the second and third elements are also quite general in nature. It is the fourth element that is the most particular and difficult to prove. This may be surprising given that the fourth element appears at first glance to be almost trivial. However, given that this element involves a non-marginal change in the dynamic general equilibrium setting, it is the one which is more involved and therefore required us to be more specific. Let us be more precise 
about each of the last three elements.

In order to understand the building blocks behind our results, it is helpful have a notation for factor input requirements for each type of technology. To this end, let $I T_{W}^{M}, K_{W}^{O}, H_{W}^{O}, H_{W}^{M}, L_{W}^{O}$ denote unit factor input requirements given a vector of factor prices W. For example, $I T_{W}^{M}$ represents the amount of IT capital per unit of output used in the modern technology given a vector of factor prices are $W$. In the particular parameterization given by Equation (2), IT $M$ is simply equal to 1 . We will maintain here- although it can also be generalized - the assumption that the modern technology uses only human capital and IT capital, while the old technology uses human capital, traditional capital and unskilled labour. Given this notation, we can say that at factor prices $W$ the modern technology is skill biased and relatively costly in terms of capital if $\frac{I T_{W}^{M}}{K_{W}^{\theta}}>\frac{H_{W}^{M}}{H_{W}^{O}}>1$. Correspondingly, we can say that the modern technology is skill biased and relative inexpensive in terms of capital if $\frac{H_{W}^{M}}{H_{W}^{O}}>1>\frac{I T_{W}^{M}}{K_{W}^{O}}$ (note that these are just definitions). As shown in the proofs in the Appendices, without using specific assumptions about the production technology, we can make the general statement that if the pre-information revolution era is characterized by the modern technology being skill biased and relatively costly in terms of capital (i.e. $\left.\frac{\frac{I T_{W}^{M}}{{ }^{O}}}{K_{W}^{O}}>\frac{H_{W}^{M}}{H_{W}^{O}}>1\right)$, then all the comparative static statements in Lemmas $1 \mathrm{~A}$ and $1 \mathrm{~B}$ follow. Furthermore, if in the post information era, the modern technology is skill biased and is relatively inexpensive in terms of capital (i.e. $\frac{H_{W}^{M}}{H_{W}^{O}}>1>\frac{I T_{W}^{M}}{\theta}$ ), then all the comparative static statements of Lemma $2 \mathrm{~A}$ and Lemma $2 \mathrm{~B}$ follow. ${ }^{19}$ Thus, the second and third elements needed to prove Propositions 1 and 2 can be viewed as quite general.

The more difficult element to show is the conditions under which a sufficiently large

\footnotetext{
${ }^{19}$ For the elements of Lemma $2 \mathrm{~B}$ to follow, we need to maintain the assumption that the elasticity of labour supply with respect to the return to education is not too large. See the discussion in footnote 15 .
} 


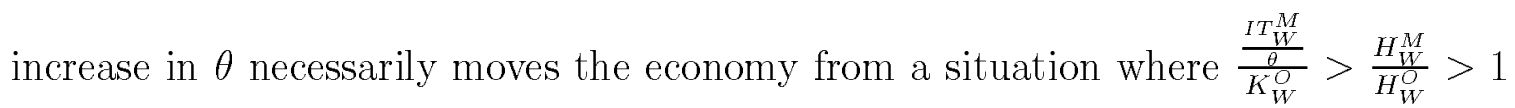
to one where $\frac{H_{W}^{M}}{H_{W}^{W}}>1>\frac{\frac{I T_{W}^{M}}{\theta}}{K_{W}^{\odot}}$. Here the particular parameterization of technologies given by Equations (1) and (2) are helpful since they reduce the above statement to showing that, for a sufficiently large increase in $\theta$, we necessarily move from a situation where $\frac{\frac{1}{\theta}}{\frac{w}{r_{K}} \cdot 5}>\frac{1}{\lambda}$ to one where $1>\frac{\frac{1}{\theta}}{\frac{w}{r_{K}} \cdot 5}$. Although we have proven this third element only for a particular parameterization, we nevertheless believe that the insight is more general. The argument is as follows. In the pre-information revolution period, when the relative price of computer based capital is high ( $\theta$ low $)$, the capital cost per unit of output produced using the modern technology will most likely be high. In this case, the factor intensity condition $\frac{I T_{W}^{M}}{\theta}=\frac{H_{W}^{M}}{K_{W}^{O}}>1$ is likely satisfied with the associated comparative static implied by Lemma $1 \mathrm{~A}$ and $1 \mathrm{~B}$. In contrast, after the information revolution, when the cost of computer based capital has fallen drastically, the capital cost per unit of output produced using the modern technology is likely to be low. In this case, the factor intensity conditions $\frac{H_{W}^{M}}{H_{W}^{O}}>1>\frac{I T_{W}^{M}}{K_{W}^{O}}$ are likely to be satisfied implying the comparative static results stated in Lemma $2 \mathrm{~A}$ and 2B. In other words, a drastic fall in the cost of computer based capital is likely to cause a factor reversal of the type where capital costs were initially relatively high for the modern versus older technology but become relatively low over time. Thus, over time the skill biased aspect of the modern technology becomes dominant. Our approach has been to show this intuition is in effect entirely verified for the simple and tractable case where the technologies satisfy Equations (1) and (2). ${ }^{20}$

\footnotetext{
${ }^{20}$ In a deep sense, there is nothing theoretically new in our approach since we are simply illustrating how a factor reversal can cause drastic changes in the functioning of an economy, which is a rather well known phenomena for trade theorists. However, in an applied sense, what is new in this paper is that we are showing why the reduction in computer based capital can, in and of itself, cause a factor reversal that is precisely of a type which can account for many of the observed differences in economic performance across countries.
} 


\subsection{Related Literature}

There are two main strands of literature related to this paper. On the one hand, there is the literature aimed at explaining recent changes in the wage structure (Example: Katz and Murphy (1992), Bound \& Johnston (1992), Acemoglu (1998,99), Beaudry \& Green (1998,2000), Caselli (1999), Heckman, Lockner, Taber (1999)). This literature has focused primarily on explaining the observed increase in the returns to education in the US. On the other hand, there is the literature which examines how reductions in the cost of computers (or equipment more generally) can explain a set of recent phenomena (Ex. Greenwood \& Yorukoglu (1997), Greenwood, Hercowitz and Krusell (1997), Greenwood \& Jovanovic (1999), Krusell, Ohanian, Rios-Rull and Violante (2000)). In particular, the paper by Krusell, Ohanian, Rios-Rull and Violante (2000) bridges these two literatures by examining the extent to which the decrease in the cost of equipment, due to capital skill-complementarity, can account for the increased returns to education observed in the US. Since this later paper is most closely related to our discussion, and because it emphasizes effects that may appear opposite to those implied here, we want to highlight the similarities and differences between the two approaches. It should be immediately noted that the paper by Krusell \& al. does not address the same issue as the one emphasized here, and therefore a comparison is not straightforward.

The main similarities between our model and that of Krusell et al. involve the factor environment. In particular, both papers use the same four factors of production, and both approaches assume that computer based capital is complementary to skilled labour. Furthermore, the relative cost between the two types of capital is treated as an exogenous variable. The main differences between the two modeling approaches involve differences in the specification of factor supply decisions, and differences in the specification of the aggregate technology. Although the differences in the specification of factor supplies has bearing on the issue at hand, we think that the most important 
and relevant difference involves the specification of the aggregate technology. Hence we will focus on clarifying how our results would be different if we adopted Krusell and al's specification of aggregate technology as opposed to our approach where the aggregate technology is determined endogenously in response to firms' optimal choice of techniques. Furthermore, we will indicate how the two approaches can be differentiated empirically. For ease of presentation, we will maintain our notation and use the production function $F^{A}(K, I T, H, L)=K^{\alpha_{1}} H^{\alpha_{2}}(a I T+(1-a) L)^{1-\alpha_{1}-\alpha_{2}}$ as representative of that used by Krusell and al.. ${ }^{21}$

Let us first emphasize that in our model there is a well defined aggregate production function that can be compared with the one used in Krusell and al.. In effect, the aggregate production is our model is simply the envelope function $F(K, I T, H, L)$ defined by $F(K, I T, H, L)=\max _{H^{\circ}, H^{M}} F^{O}\left(K, H^{O}, L\right)+F^{M}\left(I T, H^{M}\right)$ s.t. $H^{M}+H^{O}=$ $H$. However, it is not very illuminating to compare $F^{A}(K, I T, H, L)$ directly with $F(K, I T, H, L)$. Instead, what is interesting is to compare the implications of each of these two aggregate production functions for the relationship between the return to education and the aggregate capital stock, defined as $\tilde{K}=K+\frac{I T}{\theta}$, since it is the aggregate capital stock which is affected by population growth. To this end, let us define $\tilde{F}^{A}(\tilde{K}, H, L, \theta)$ as the envelope function given by $\max F^{A}(K, I T, H, L)$ s.t. $\tilde{K}=K+\frac{I T}{\theta}$, and let $\tilde{F}(\tilde{K}, H, L, \theta)$ be defined in a similar fashion. These two new production functions, which are given below, are simply the aggregate production functions defined over the aggregate capital stock, assuming that the aggregate capital stock is efficiently allocated between traditional capital and computer based capital. Since both models assume that capital is efficiently allocated, these two reduced form production functions are relevant aggregate production functions. ${ }^{22}$

\footnotetext{
${ }^{21}$ This is a special case of the production function specified in Krusell and al. We choose this special case since it allows to make the comparison most easily.

${ }^{22}$ These functions are convex and hence an increase in a factor necessarily reduces it own marginal product. Furthermore, since these function satisfy CRS, their derivatives only depend the ratios $\frac{\tilde{K}}{L}$ and $\frac{H}{L}$. Note that we only report the specification of the function $\tilde{F}(\tilde{K}, H, L, \theta)$ for factor profiles where both technologies are in use and where all factor prices are positive.
} 


$$
\begin{gathered}
\tilde{F}^{A}(\tilde{K}, H, L, \theta)=L\left(\left(\frac{\theta\left(1-\alpha_{1}-\alpha_{2}\right)}{1-\alpha_{1}}\right)^{1-\alpha_{1}-\alpha_{2}}\left(\frac{\alpha_{2}}{\left(1-\alpha_{1}\right)(1-a)}\right)^{\alpha_{2}} \frac{H^{\alpha_{1}}}{L}\left((1-a) \frac{\tilde{K}}{L}+\frac{a}{\theta}\right)^{1-\alpha_{1}}\right) \\
\tilde{F}(\tilde{K}, H, L, \theta)=L\left(\lambda \frac{H}{L}+\frac{(1-\lambda) \lambda}{2 \theta}+(1-\lambda)\left(\frac{\lambda^{2}}{4 \theta^{2}}+\frac{\tilde{K}}{L}-\frac{\lambda H}{\theta L}\right)^{.5}\right)
\end{gathered}
$$

We can now compare the implication of each model for the returns to education, $\frac{r_{H}}{w}$, as given by the ratio of marginal products. For the specification used by Krusell and al., the relationship between returns to education and factor use is given by:

$$
\frac{r_{H}}{w}=\frac{\tilde{F}_{H}^{A}(\tilde{K}, H, L, \theta)}{\tilde{F}_{L}^{A}(\tilde{K}, H, L, \theta)}=\left(\frac{\theta(1-a) \alpha_{1}}{a\left(1-\alpha_{1}\right)}\right) \frac{\tilde{K}}{H}+\frac{\alpha_{1}}{\left(1-\alpha_{1}\right)} \frac{L}{H}
$$

As can be seen, with the specification used by Krusell and al., an increase in $\frac{\tilde{K}}{H}$ (holding $\frac{l}{H}$ fixed) is always associated with an increase in the returns to education, even though they justify only the assumption that $I T$ capital increases the returns to skill. In contrast, in our model the signs of $\frac{\partial \frac{r_{H}}{w}}{\partial \frac{\tilde{K}}{H}}$ changes depending on whether we are in the pre or post information revolution era. In effect, the signs of $\frac{\partial \frac{r_{H}}{w}}{\partial \frac{K}{H}}$ in our model is directly related to whether or not the capital cost associated with the modern (skill biased) technology is relatively high. In particular, in the pre-information revolution era, the sign of $\frac{\partial \frac{r H}{w}}{\partial \frac{K}{H}}$ is positive which is why Lemma $1 \mathrm{~A}$ states that countries with high population growth (which have lower ratios of $\frac{\tilde{K}}{H}$ ) are associated with lower returns to education. However, the opposite is true in the post-information revolution era, that is, in the post-information revolution era of our model $\frac{\partial \frac{r_{H}}{\nu}}{\partial \frac{\bar{K}}{H}}$ is negative and hence high population growth economies are predicted to exhibit greater returns to education. It is this effect which is central to our mechanism. In particular, the reason we obtain the comparative statics given in Propositions 1 and 2 is that, by adopting a framework with endogenous technological choice, we are allowing the pattern of factor substitution to be determined endogenously and thereby change in response to 
the information revolution. Obviously, it is an empirical issue whether, in the post information revolution era, an increase in the aggregate capital stock is associated with an increase or a decrease in the returns to education. It is interesting to note that Flug and Hercowitz (2000) find, as assumed in our framework, that different types of investments have opposite effects on the demand for skilled labour. In effect, Flug and Hercowitz (2000) report that equipment investments increase the relative demand for skilled workers while other investments reduce this relative demand. Moreover, the cross-country evidence presented in Beaudry \& Green $(1998,2000)$ provides support for the view that, in aggregate, increases in capital intensity are associated with a decrease in the returns to education over the period of interest, as opposed to an increase as assumed in Krusell and al..

\section{Some Empirical Evidence}

Propositions 1 and 2 summarize the implications of our model in terms of how crosscountry differences in population growth translate into differences in wage and employment growth arising over the course of the information revolution. The means we choose to examine these implications is to first perform a case study based on observed developments in West Germany, the United Kingdom and the United States since the mid seventies, and then to look more widely at the effects of population growth in a broader set of industrialized countries. The first approach has the advantage that we can use individual level data to construct wage variables that are more reliable and closely related to the theory; while the second approach has the advantage of highlighting patterns across a wider set of countries, albeit with less appropriate data.

Recall that the key common force in our model is the decline in the cost of using computer based technology. It is the interaction of this force with differences in population growth rates that we believe explains many of the differences in recent economic 
performance across industrialized countries. To provide a sense of the importance of the fall in the price of information technology, we plot Jorgensen and Stiroh(1999)'s series on the price of investment in computers in the US in Figure 1. This series is the result of their extensive work using specific categories of capital investment. ${ }^{23}$ The plot conveys the dramatic decline in the price of computers. There is clearly a "revolution" in the price to firms of investing in computers over this period.

\subsection{A Case Study of West Germany, the United Kingdom and the United States}

The object of this section is to examine the evolution over recent history of a set of economic variables - where each is an empirical counterpart to those stated in Proposition 1 and 2 - for three major industrialized countries: the US, (former west) Germany and the UK. ${ }^{24}$ Our interest in these three countries is that they provide a good platform on which to compare the relevance of our theory to a stylized institutional explanation. Recall that the standard institutional explanations for differences across countries argue that developed countries have face similar underlying technological changes over the recent period but that differing institutions have translated these into different patterns for labour market outcomes.

To begin, in Table 1 we report average population growth for these three countries over the period 1960-97. As can be seen, trend population growth in the UK and in West-Germany were rather similar from the sixties to the nineties, and are again

\footnotetext{
${ }^{23}$ Jorgensen and Stiroh use BEA data, combining investment data on mainframe computers, personal computers, direct access storage devices, printer, terminals, tape drives, and storage devices into a single "computer" series. They use the BEA estimated price indices which hold the quality of this equipment constant.

${ }^{24}$ In Beaudry and Green (2000), we propose and implement (using US and German data) a more structural approach to evaluating a model which has properties akin to those used to derive in Lemma $2 \mathrm{~A}$. In this sense, the evidence presented in Beaudry and Green (2000) should be viewed as complementary to that presented here. In particular, the reader interested in a more formal means of evaluating elements of the current theory should refer to that paper.
} 
Table 1: Annual Population Growth (\%)

\begin{tabular}{||c|c|c|c||}
\hline \hline & W. Germany & United Kingdom & United States \\
\hline $1965-90$ & 0.33 & 0.25 & 1.2 \\
$1975-90$ & 0.15 & 0.16 & 1.0 \\
$1990-97$ & $0.27_{(97-92)}^{*}$ & 0.13 & 1.0 \\
\hline \hline
\end{tabular}

rather similar since German unification. We omit the 91-92 period for West Germany from our calculations of population growth since it represents a one time jump in population, as opposed to a change in trend population growth. In contrast, the trend rate of population growth in the US was of the order of 4 to 6 times greater over this period. Hence, our theory would predict that wage and employment outcomes for Germany and the UK should be quite similar to each other but systematically different from the US. In comparison, the institutional view suggests that the US and the UK experiences should have been more similar over the period, since they have more flexible institutions, whereas the German experience should be the outlier.

Our choice of the time period over which to compare labour market outcomes for these three countries is driven by both theory and data availability. On the one hand, the theory has predictions for cross-country differences in changes in economic outcomes; where the change should be measured from a point in time just before the mass affordability of computers and ending at a point in time sufficiently distant to allow firms and individuals to adjust. Therefore, an appropriate starting point appears to be somewhere around the mid seventies, since the first user-friendly computer (the Apple) was introduced in 1976 and it was made widely available in most industrialized countries within a few years. Greenwood and Yorukoglu (1997) suggest 1974 as the relevant break year. The best end point is probably as close as possible to the present. On the other hand, we are restricted by data which will not always allow us to start as early as we wish. 
We begin by portraying movements in the wage structure in the three countries. ${ }^{25}$ Recall that in terms of wages, the theory has implications for movements in both the price of unskilled labour as well as the returns to education. Such movements in the structure of wages can be captured by estimating linear $(\log )$ wage-education profiles, where movements in the intercept capture movements the price of unskilled labour, while movements in the slope captures movements in the returns to education. ${ }^{26}$ Since the UK and Germany have similar rates of trend population growth, the theory implies that the UK and Germany should exhibit similar patterns for changes in both the intercepts and slopes of (log)wage-education profiles, while the US should exhibit a poorer performance in terms of changes in the intercept of these profiles and a greater increase in the slope.

We obtain relevant data (hourly wages, education levels, gender, etc) for the US from the Panel Study on Income Dynamics (PSID) and for Germany from the German Socio-Economic Panel (GSOEP). Both are panel datasets in which a set of families and their off-shoots are followed across time. We make use of an Equivalence File constructed by GSOEP researchers which provides comparable data constructs from the PSID and the GSOEP. ${ }^{27}$ The PSID data in the equivalence file is available from 1979 to 1996 , while the GSOEP data is available from 1983 to $1996 .{ }^{28}$

The UK data we use comes from General Household Survey (GHS) for the years 1979 to $1996 .{ }^{29}$ The GHS is a representative survey of individuals in England, Scotland and Wales. It is based on a survey of between ten and twelve thousand

\footnotetext{
${ }^{25}$ Throughout our discussion, we focus on the former West Germany both before and after reunification. This allows us to make more consistent across time comparisons.

${ }^{26}$ If wages are equal to $w+r_{H} h$, the $\log$ wages are approximately equal to $\log (w)+\frac{r_{H}}{w} h$, hence the intercepts from estimating log-wage education profiles capture changes in the price of unskilled labour while change in the slope capture changes in the return to education.

${ }^{27}$ These files are constructed and maintained by the German Institute for Economic Research, The Department of Policy Analysis and Management at Cornell University, and the University of Michigan.

${ }^{28} \mathrm{We}$ do not take advantage of the panel nature of the data, using it as a series of cross sections. In each case, the data are not perfectly representative of the population as a whole and therefore we make use of weights provided in the data sets in all our calculations.

${ }^{29}$ We thank David Card for helping us get access to the GHS data.
} 
households per year and is conducted continuously throughout the year. Information is collected on personal demographic and labour market data for a respondent with some added information on the head of household and spouse. However, education data, which is central to our analysis, is collected only for the main respondent and so we focus on their data. ${ }^{30}$

For all three countries, we use data for all individuals between the ages of 16 and 65. Our wage measure in each case is the hourly wage. This is constructed by dividing total annual labour earnings by annual hours of work as reported in the Equivalence File for the US and Germany. For the UK it is constructed using annual earnings, weeks worked and usual hours per week variables ${ }^{31}$ The constructed hourly wages are deflated using a country specific GDP deflator.

A potential concern in discussing wage-education profiles for these three countries is the comparability of years of education measures across datasets. For the US, the years of education measure is based on an answer to a question about the highest number of years of schooling completed. For West Germany, years of education is a constructed variable based on norms for various reported completed levels of education. The years of schooling variable in the Equivalent File contains an attempt to generate a measure that is comparable to the US measure and includes attempts to account for educational contributions from apprenticeship programmes. For the UK we use Schmidt(1995)'s generated variable which essentially equals the age the individual left full-time education minus 5. While these are attempts to generate comparable education measures, the results are undoubtedly not perfectly comparable. However, we analyse within country patterns separately, effectively allowing for different wage levels and education differentials across countries. Our key assumption

\footnotetext{
${ }^{30}$ There are no reported sampling weights in the version of the GHS we use and thus the UK data is not reweighted in any of our estimation.

${ }^{31}$ In the GHS before 1982, usual hours are divided into regular and overtime hours. Plots of the data suggest to us that the best match to the post-1982 GHS data is created by using only regular time hours before 1982 .
} 
is that we can meaningfully compare time patterns in wage levels and wage-education differentials across countries even if we do not regard comparisons of the levels and differentials in a given year as necessarily very informative.

In order to summarize the main wage-education patterns, we regress the log of the hourly wage on a full set of year dummy variables, the number of years of education, the interaction of education and the dummy variables, and a full set of dummy variables corresponding to five year age categories. We run this regression separately for each country. The result is a separate wage-education profile for each year for each country, holding constant country-specific age effects. ${ }^{32}$ We use only male wages in order to construct indexes of the prices of labour and education that are free from composition bias relating to increases in female labour force participation. Since these movements are quite different across the three countries, we were particularly concerned about any such biases in trying to make comparisons across countries.

Rather than plotting the profiles themselves, in Figures $2 \mathrm{~A}$ and $2 \mathrm{~B}$ we summarize the data by plotting the intercepts and slopes of the wage-education profiles associated with each country. We normalize all series to 1 in 1979 to focus attention on time patterns within each country. ${ }^{33}$ We interpret the intercept terms, which correspond to wages at 9 years of education, as the unskilled wage. This appears to be a reasonable benchmark for the unskilled wage since it is close to the minimum level of education attained in these economies. The slope corresponds to the returns to education. Figure 2 shows a striking similarity between the time patterns of low skilled wages for Germany and the UK, but a large difference between those countries and the US. For the entire period (from 1979 to 1996), the US shows a $30 \%$ decline in low skilled wages while both Germany and the UK experience approximately $10 \%$

\footnotetext{
${ }^{32}$ We repeated this exercise using higher order terms in education but, similar to other studies, found that a linear wage-education profile is a remarkably good description of the data. We chose to discuss the linear profile because it makes the observed patterns more transparent.

${ }^{33}$ We do not have data for the years 1979 to 1983 for the Germany. We therefore extrapolate these values based on a regression of the intercept terms estimated for the years 1983 to 1996 on a linear trend. We obtain values for the slope parameter for the years for Germany in a similar way.
} 
increases. The differences in the education differentials are also striking: while the US experienced a large increase in the differential, the UK experienced only a slight increase and Germany only a slight decline. These results fit with earlier findings in other papers. In particular, the sharp increase in the education differential over this period is one of the main stylized facts associated with increased inequality in the US (see, e.g., Juhn, Murphy, and Pierce (1993)). The fact that this occurs with a sharp drop in low skilled wages fits with results in MaCurdy and Mroz(1995) and Beaudry and Green(1998) using CPS data which show that the increased education differential occurred mainly because of falls in the wages of the low educated, with little increase in high education wages. Thus, the depicted wage pattern for the US fits with results from earlier research. Similarly, the patterns for the UK fit with findings in Gosling et. al.(1999) who report an increase in the educational differential of only about $5 \%$ between individuals with an University Degree versus A levels over the entire eighties, which is consistent with the very small increase in the returns to education depicted in our figures. Hence, even though it is often thought that wage-education profiles moved rather similarly in the US and the UK over this period, a closer look at the data suggests actually that it is the UK and German experience in terms of wageeducation profiles that appear most similar, and that the US experience appears to be an outlier. ${ }^{34}$

Movements in wage patterns, of course, are only part of our story. We are also interested in changes in employment patterns. In Figure 3A, we present changes in the employment rate ${ }^{35}$ by country. It is clear that the country specific patterns plotted in Figure 3 are quite different. While the US employment rate grows by over 15\% from 1975 to 1997, both the West German and UK rates show virtually no trend growth. The UK rate shows somewhat more dramatic cyclical patterns than the other

\footnotetext{
${ }^{34}$ One aspect of the data that our model do not address is changes in within group inequality. In effect, we believe that institution differences between these countries may be important for understanding this dimension of the data.

${ }^{35}$ These are defined as total employment divided by the population aged 15 to 64 . Once again, the German data refers only to West Germany.
} 
countries. Once again, consistent with our theory, the two slower population growth countries - Germany and the UK - experience rather similar changes in the rate of employment over the course of the information revolution; while the US, with higher population growth, is the outlier with a strong increase in the rate of employment.

Figure 3B reports the change in per capita employment in services over the period 1970 to 1997 for our three countries. As emphasized by Freeman and Schettakat (2000), the growth of services in the US was faster than in Germany, with service employment per capita growing 35\% from 1975 to 1997 in the US compared to $24 \%$ in Germany. In effect, Freeman and Schettakat argue that the differential growth in services is central to understanding the increased employment rate in the US versus Germany. From our point of view, the most interesting aspect associated with Figure 5 is again the striking similarity between the German and UK experience and, as implied by our theory, the fact that the higher population growth country- the USexperiences the greatest increase in per capita service sector employment. Our theory indicates that these differences in service sector employment patterns arises because more educated households decide to supply more labour to the market and buy more services through the market. In all likelihood, such a rise in labour supply would come predominantly from increased hours of market work for women. In order to look at this effect, in Figure 4 we plot the female employment rate from 1975 to 1997 for our three countries. As can be seen, the US has much more striking growth in female labour supply than Germany and the UK. Once again, the UK and German experience is markedly similar. Moreover, it should be noted that the different growth in female employment can account for most of the differential growth in the overall employment rate.

Recall that our theory suggests that it is population growth, through it effect on the accumulation of factors, that causes the differential wage and employment movements. In order to convey the different patterns of factor accumulation between our three countries, in Figures 5A-5D we plot respectively the growth of physical 
capital, the growth of the capital to labour ratio, the growth of the human capital to labour ratio and finally the growth of the physical capital to human capital ratio. The data for these graphs are all taken from Jorgensen and Yip (1998) and cover the period 1975-95. The attractive feature of the Jorgensen and Yip data is that it has been constructed to provide internationally comparable capital stocks for the G7 countries, with special attention to quality improvements in physical capital and labour. As we can see from Figure 5A, the growth of the physical capital stock (which takes account of quality changes) is rather similar across these three countries even if population growth is quite different. As a result, in Figure $5 \mathrm{~B}$ we see that the physical capital to labour ratio grows much slower in the US, where the increase in the employment rate is higher, than in Germany or the UK. Moreover, both Germany and the UK exhibit again surprisingly similar patterns in terms of changes in physical capital intensity.

In Figure 5C, we plot the ratio of human capital to labour (i.e., human capital intensity). ${ }^{36}$ Here we see the US exhibiting slightly more growth than either Germany or the UK, although the difference is not very large. In effect, Figure $5 \mathrm{C}$ nicely captures the difficulty associated with explaining differences in returns to education between these countries based only on changes in human capital intensity. Since these countries do not appear to differ much in their growth in human capital intensity, a model which searches to explain differential changes in wages by only emphasizing differential changes in human capital would predict the change in the US return to education over the period to be no greater than in the other two countries; which is obviously wrong. In contrast, our model suggests that it is not human capital intensity

\footnotetext{
${ }^{36}$ Jorgensen and Yip refer to this series as a labour quality series since it encompasses both changes in education and experience of the labour force. In order to check the robustness of this pattern, we built an index of human capital based only on years of education. We found that the increase in average years of education (even if we use hours of work as weights) in Germany was almost identical to that observed in the US, while the UK had a slightly greater change due mainly to the increased age of compulsory education. Since we found the ranking of human capital intensity changes between these countries to be sensitive to measurement, but always of rather minor size, we believe that it is best to summarize these countries as having similar changes in human capital intensity.
} 
by itself which explains differences in wage patterns, but instead out theory points to differential in the human capital to physical capital ratio as the essential determinant. As can be seen in Figure 5D, the ratio of physical capital to human capital grew similarly in Germany and the UK over the period, while it grew substantially less in the US. Obviously, this differential pattern in the human to physical capital ratio is due mainly, in an accounting sense, to differences in employment growth and not much to differences educational attainment.

An interesting aspect of Figures 5A-5D is its relationship with the empirical evidence presented in Beaudry and Green (2000). ${ }^{37}$ In this earlier paper, we showed how differential use of human versus physical capital between the US and Germany could explain the differential patterns in wages. In particular, we showed that the estimated relationships between wages and factor movements in and between these countries was consistent with the type of neo-classical model of technological adoption used here, and we came to the conclusion that changes in the human to physical capital ratio was likely an essential determinant of the differential evolution of wages. In this sense, our previous papers offered evidence in favour of one piece of that structure embedded in the current model, that is, the link between factor accumulation, technological adoption and wage determination in the post information era. In effect, our current model can be thought as having two major structural steps: step 1) from population growth to factor accumulation and, step 2) from factor accumulation (through technological adoption) to wages. Correspondingly, Figures 5A-5D complement our previous evidence regarding step 2) by illustrating patterns of factor accumulation between the US, Germany and the UK which give support to step 1), that is, that high population growth-through it effect on employment growth-leads to differential patterns of factor accumulation.

From Figures 1 through 5, we conclude that the US, German and UK experiences provide interesting prima facie support for our theory in the sense that the

\footnotetext{
${ }^{37}$ See also Beaudry \& Green (1998).
} 
two low population growth countries have shared, over the course of the information revolution, rather similar changes in wage profiles, employment patterns and factor intensities. While, in contrast, the higher population growth country has experienced a poorer performance in terms of the wage of less skilled workers, a much greater increase in the returns to education, a greater increase in the employment rate and a smaller increase in the physical capital to human capital ratio. Nonetheless, as with any case study, this evidence only covers a limited sample. Hence, in the next section, we take the necessary step towards a generalization by examining the relevance of the simplest reduced form implications of our model-that is the relationships between population growth, employment and wages- using the entire set of rich industrialized countries.

\subsection{Changes in Employment, Wages and Population Across Industrial- ized Countries}

As should now be clear, our model suggests that, over the course of the information revolution, changes in employment and wage patterns across industrialized countries should be systematically linked to differences in rates of population growth. In this section, we present evidence to this effect based on the sample of 18 OECD countries with per capita GDP above $10000 \$$ US in $1985 .^{38}$ Our goal is to look at the relationship between employment, wages and population growth before and after 1975 as a means of examining the relevance of the theory. Obviously, it would be desirable to have very detailed data on wages and employment for the entire set of countries over a long period of time. However, this is not possible. Our choice therefore to focus on two summary measures of economic performance for which data is readily available for most of these countries since 1960. The two measures are the employment

\footnotetext{
${ }^{38}$ The countries are Australia, Austria, Belgium, Canada, Denmark, Finland, France, West Germany, Iceland, Italy, Japan, Netherlands, New Zealand, Norway, Sweden, Switzerland, United Kingdom, United States. We excluded Luxembourg from our sample since we could not access the relevant wage data.
} 
rate $^{39}$ and real wages (measured as real compensation per employee) ${ }^{40}$ We begin by examining the relationship between (annualized) changes in the employment rate and population growth since this relationship is easily related to the theory. In effect, Proposition 2 suggests the emergence of a positive association between changes in the employment rate and population growth over the course of the information revolution. In contrast, our model does not have an unambiguous prediction with respect to the behaviour of the average wage . Recall that there are three elements that enter the average wage: the price of unskilled labour $w$; the price of skill $r_{H}$; and the average level of education $h$. Our theory predicts that, over the course of the information revolution, high population growth will be associated with low growth in $w$. However, it does not yield clear predictions for cross- country patterns in changes in either $r_{h}{ }^{41}$ or $h$. Nonetheless, we will examine - as if an implication of the theorywhether high population growth economies have been particularly associated with low real wage growth since the mid-seventies, knowing that we are actually imposing more on the theory than what is formally predicted. Clearly, it would be preferable to have a measure of the price of unskilled labour instead of average wages, but such a measure is not readily available for this set of 18 countries over a long period of time. $^{42}$

\footnotetext{
${ }^{39}$ We measure the employment rate as the fraction of employed individual among the population $15-65$. The data are from the 1999 OECD Statistical Compendium, Annual Labor Force statistics.

${ }^{40}$ The data are from the 1999 OECD Economic Outlook. The OECD Economic Outlook directly reports real compensation per employee. When available, this is the measure we used. If it is not available, which is the case only in part of the pre- 75 sample, we constructed real compensation per employee by dividing total compensation by the number of employees and deflating by the GDP deflator. We checked the robustness of our results by considering alternative wage measures, such as hourly wages in manufacturing, and found that the results are robust to such changes. Note, though, that we had less scope to verify the robustness of our results for the period 1960-1974.

${ }^{41}$ Note that the theory has an unambiguous prediction for $\frac{r_{h}}{w}$, but not for $r_{h}$ alone.

${ }^{42}$ For example, wage data for non-production workers in manufacturing, which could be argued to be a better proxy for the unskilled wage, is not available for all these countries over this period (it is only available for about half these countries and for shorter periods of time). Nonetheless, for the available subset of countries, we examined whether average wage growth was an unbiased predictor of wage growth for non-production workers in manufacturing. We found this to be the case and hence it supported are view that cross-country differences in average wage growth are likely dominated by changes in the price of unskilled labour.
} 
Table 2 reports cross-sectional estimates of the effect of population growth on changes in the employment rate, where changes are calculated over the entire period of interest (a long-difference) and then annualized. In Column 1, we report an estimate for the period prior to information revolution, that is, over the period 1960 to 1974. The results in the table reveal no systematic relationship between population growth $^{43}$ and changes in the employment rate over this period. In Column (2), we report the estimate of the same effect for the period 1975-1997, that is, we report the regression coefficient associated with regressing the (annualized) long-difference in the employment rate between 1975 and 1997 on the (annualized) population growth rate over the same period. In contrast to Column (1), in Column (2) we now find a positive and significant relationship between population growth and the employment rate. Since positive employment rate changes may generate immigration and hence population growth, in Column (3) we re-estimate the relationship over the post 1974 period using the population growth over the 1960-74 period as an instrument. ${ }^{44}$ The estimate in Column (3) is almost identical to that in Column (2) and hence does not suggest that the observation is driven by reverse causality. Finally, in Column (4) we omit the United States from the sample in order to show that the result is not driven by this observation alone. Together, we take the results of Table 2 as indicating that, over the period of the information revolution, there appears to have emerged a systematic and positive relationship between population growth and employment rate changes as predicted by our theory.

In Table 3, we report estimates of the relationship between the percentage changes in real wages (measured as the real compensation per employee) and population growth. We again begin by examining the relationship over the 1960-74 period. However, before discussing these estimates, it is relevant to first recall what standard neo-classical growth theory suggests regarding this relation. In effect, there are two cases. The simplest case is when countries are on their balanced growth path. If this

\footnotetext{
${ }^{43}$ We use the growth of the population $15-64$ as our measure of population growth.

${ }^{44}$ The $R^{2}$ for the first stage regression is .5
} 
is the case, the Solow growth model does not predict any systematic relationship between wage growth and population growth. In contrast, on the transitional path, the theory is consistent with a negative relationship between wage growth and population growth, but this coefficient should go to zero over time as convergence is achieved. Finally, in the case where transitional dynamics are thought to be important, the standard approach is to include initial GDP per capita as an additional regressor to capture the forces of convergence.

In Column (1) of Table 3, we report our cross-sectional estimates of the relationship between wage growth and population growth over the period 1960-1974, in the absence of any additional regressors. ${ }^{45}$ In column (2) we add the 1960 level of per capita gdp (in $\log$ form) as an additional regressor ${ }^{46}$ The results reported in Column (1) and (2) are interesting in that they are very much in line with neo-classical growth theory. First, in Column (1), we find a point estimate of the effect of population growth on wage growth of approximately .3. Although this coefficient is not statistically significant, it is of a size easily consistent with neo-classical growth theory. In Column (2), we find a very significant effect of initial GDP on wage growth, but again find an insignificant effect of population growth. Our point estimate of catch up is $2 \%$ per year which is remarkably similar to that found in the growth literature. Hence, we conclude that prior to the information revolution, the relationship between wage growth and population growth is rather weak among industrialized countries even though there is evidence of transitional dynamics forces (convergence). Moreover, neo-classical growth theory would suggest that in a subsequent period, the effect of population growth on wage growth should diminish (when not controlling for convergence) since convergence should be less important.

\footnotetext{
${ }^{45}$ The OECD Statistical Compendium does not report sufficient employee compensation data for Iceland and hence it is omitted from our sample. Moreover, in the 1960-74 period, the data for Finland, the Netherlands and New Zealand were too incomplete to be included the sample. Hence, over the early period, we only have 14 observations, while we have 17 observations over the $1975-97$ period.

${ }^{46}$ This variable is taken from Barro and Sala-i-Martin (1995).
} 
Columns (3) and (4) of Table 3 are the analogues to Columns (1) and (2) for the period of the information revolution. As with the case of the employment rates, there appears to be a drastic change in the effects of population growth in the post 1974 period as compared to the pre-1975 period. In Columns (3) and (4), our estimates of the effect of population growth on wage growth are now much greater in size, very significant and independent of whether or not we include GDP per capita as additional regressors. ${ }^{47}$ Moreover, we find that population growth actually explains an important fraction of the cross-sectional variance, and there is no longer strong evidence of catch up. ${ }^{48}$ In Columns (5) and (6), we instrument population growth over the period 1975-97 with population growth over 1960-74. Again, we do not find evidence of simultaneity bias and, as is often the case with IV estimation, our point estimates are slightly increased (in absolute value) by this procedure. In Columns (7), we repeat the exercise using hourly wages in manufacturing as our wage measure instead of real compensation per employee. We only report the case where we estimate the univariate relationship by instrumental variables, since the other cases give similar very results. In all further cases, we focus only the IV estimates.

Our finding of a strong negative association between population growth and wage growth over the $1975-97$ period is robust to several extensions. For example, we found this observation to always be robust to the exclusion of the United States from the sample. Furthermore, we found the relationship to be robust to the inclusion of a dummy variable for Anglo-Saxon Countries (Australia, Canada, New Zealand, United Kingdom, United States) and a dummy variable for Scandinavian Countries (Denmark, Norway, Sweden). In fact, as can be seen in Row (8) where these two dummy variables are included, the addition of these dummies barely affects our point estimates. ${ }^{49}$. Finally, in Row (9) we include the change in the employment rate

\footnotetext{
${ }^{47}$ If we use the growth in hourly wages in manufacturing as our dependant variable, we again find an estimate of -1.08 (s.e. .4) for the effect of population growth.

${ }^{48}$ If we exclude population growth, we find a significant effect of 1960 GDP per capital on wage growth ( $1 \%$ catch up rate) but we don't find a significant effect if we use a more recent measure of GDP per capita.

${ }^{49}$ We can go even one step further and exclude all non-European countries from the sample and maintain
} 
as an additional regressor. Interestingly we see that, consistent with our theory, population growth has an effect on wage growth beyond that induced by a change in the employment rate. In summary, over the $1975-97$ period there appears to to have emerged a sizable and systematic relationship between population growth and changes in wage and employment patterns. In particular, the $1975-97$ patterns are surprising given the observations over the 1960-74 period and are therefore difficult to reconcile with a Solow type growth model. However, such a change in pattern after 1975 is consistent with the type of structural transformation suggested by our model as a results of a drastic decline in the price of computer based capital.

\section{Conclusion}

In this paper, we have illustrated how differences in population growth can offer a rather simple unified explanation to many cross-country differences in recent economic performance. In particular, we have shown theoretically how population growth can accelerate the process of adoption of new technology and thereby lead such countries to exhibit a more profound change in economic outcomes during the information revolution. Our model offers an explanation for why high population growth economies, like the US, appear particularly technologically dynamic in the recent era - especially in comparison to their relative performance in the seventies - both in terms of the adoption of computers and in adoption new forms of work organization. Furthermore, since we view this process of technological adoption as endogenous and hence of variable speed across countries, it offers an explanation for cross country differences in wage outcomes as well as the growth of the service sector. We have also provided some empirical evidence in support of the theory. Obviously, there are important aspects of cross-country differences in economic performance that our model

a dummy variable for Scandinavian countries. Even in this case, we get a similar estimate of the effect of population growth 
has not addressed ${ }^{50}$ (example: within group inequality and unemployment) and there are good reasons to believe that other forces, such as institutions and globalization, play a role in determining economic outcome. Nonetheless, we believe that our theory and the associated empirical evidence suggests that differences in population growth may be a key element for understanding cross-country differences in recent economic performance. ${ }^{51}$

\footnotetext{
${ }^{50}$ On the theoretical front, one of the limitations of our model is that we do not endogenize the relative price of computers. The paper by Acemoglu (1998), Kiley (1999) and Duranton (1999) explore mechanisms that may help understand this phenomena.

${ }^{51}$ We believe that institutional differences across countries are likely important for explaining cross-country differences in either unemployment rates or within group inequality. The reason we have such a belief is derived from observations like that of Lee (1999) showing how changes in the minimum wage have played an important role in generating within group inequality in the US. Similarly, Card \& Riddell (1995) show that differences in institutions between Canada and the US appear to have been more important for explaining differences in unemployment rates than differences in rates of employment. Hence, in order to explain either within group inequality or unemployment rates, we believe that it would be necessary to enrich our model to include institutions and possibly political economy considerations.
} 
Table 2: Cross-Country Est. of Effect of Pop. growth on Emp. Rate

\begin{tabular}{||c|c|c|c|c||}
\hline \hline & $\begin{array}{c}\text { Const. } \\
\text { (s.e) }\end{array}$ & $\begin{array}{c}\text { Pop. Growth } \\
\text { (s.e.) }\end{array}$ & $R^{2}$ & N. Obs. \\
\hline $1960-74$ & & & & \\
\hline$(1)$ & -.001 & .074 & .062 & 18 \\
$(.001)$ & $(.072)$ & & & \\
\hline $1975-97$ & & & .272 & 18 \\
\hline$(2)$ & -.001 & 0.286 & & \\
& $(.001)$ & $(.117)$ & .257 & 18 \\
$(3)$, IV & -.002 & 0.306 & & 17 \\
& $(.001)$ & $(.130)$ & .229 & 17 \\
$(4)$, IV & -.002 & 0.280 & & \\
& $(.001)$ & $(.135)$ & & \\
\hline \hline
\end{tabular}

1. The dependant variable is the change in the employment rate over the period 1975-97 (annualized), that is, the long-difference in the ratios of the employed population to the total population 15 to 65 . The countries in the sample are Australia, Austria, Belgium, Canada, Denmark, Finland, France, W. Germany, Iceland, Italy, Japan, Netherlands, New Zealand, Norway, Sweden, Switzerland, United Kingdom, United States. For West Germany, changes are calculated over the period 1975-91 instead of 1975-97 and then annualized.

2. Population growth is the annualized percentage change in population 15 to 64 . When estimating by IV, population growth over the period 1960-74 is used to instrument population growth over the period 1975-97.

3. In Row (4), the US observation is omitted from the sample 
Table 3: Cross-Country Est. of Effect of Pop. growth on Wage Growth

\begin{tabular}{|c|c|c|c|c|c|c|}
\hline & $\begin{array}{c}\text { Const. } \\
\text { (s.e) }\end{array}$ & $\begin{array}{c}\text { Pop. Growth } \\
\text { (s.e.) }\end{array}$ & $\begin{array}{c}\text { GDP-60 } \\
\text { (s.e.) }\end{array}$ & $\begin{array}{c}\Delta \text { Emp.rate } \\
\text { (s.e) }\end{array}$ & $R^{2}$ & N. Obs. \\
\hline \multicolumn{7}{|l|}{$1960-74$} \\
\hline (1) & $\begin{array}{c}.035 \\
(.004)\end{array}$ & $\begin{array}{l}-.327 \\
(.290)\end{array}$ & - & - & .096 & 14 \\
\hline$(2)$ & $\begin{array}{c}.245 \\
(.050)\end{array}$ & $\begin{array}{l}-.149 \\
(.192)\end{array}$ & $\begin{array}{l}-.024 \\
(.006)\end{array}$ & - & .653 & 14 \\
\hline \multicolumn{7}{|l|}{$1975-97$} \\
\hline (3) & $\begin{array}{l}.020 \\
.002\end{array}$ & $\begin{array}{l}-1.01 \\
(.260)\end{array}$ & - & - & .520 & 17 \\
\hline (4) & $\begin{array}{c}.071 \\
(.041)\end{array}$ & $\begin{array}{l}-.926 \\
(.273)\end{array}$ & $\begin{array}{l}-.006 \\
(.005)\end{array}$ & - & .569 & 17 \\
\hline$(5)$, IV & $\begin{array}{l}.021 \\
.002\end{array}$ & $\begin{array}{l}-1.18 \\
(.266)\end{array}$ & - & - & .568 & 17 \\
\hline$(6), \mathrm{IV}$ & $\begin{array}{c}.082 \\
(.036)\end{array}$ & $\begin{array}{l}-1.06 \\
(.261)\end{array}$ & $\begin{array}{l}-.007 \\
(.005)\end{array}$ & - & .641 & 17 \\
\hline$(7)$, IV & $\begin{array}{l}.021 \\
.004\end{array}$ & $\begin{array}{l}-1.17 \\
(.497)\end{array}$ & - & - & .317 & 14 \\
\hline$(8), \mathrm{IV}$ & $\begin{array}{c}.023 \\
(.041)\end{array}$ & $\begin{array}{l}-1.11 \\
(.273)\end{array}$ & - & - & .707 & 17 \\
\hline$(9)$, IV & $\begin{array}{l}.020 \\
.002 \\
\end{array}$ & $\begin{array}{l}-.990 \\
(.291)\end{array}$ & - & $\begin{array}{l}-.670 \\
(.494)\end{array}$ & .622 & 17 \\
\hline
\end{tabular}


1. The dependant variable is the growth in real compensation per worker over the entire period 1975-97 (annualized). Row ( 7 ) is an exception, where the dependant variable is the percentage change in the hourly wage in manufacturing. The countries in the sample are Australia, Austria, Belgium, Canada, Denmark, Finland, France, W. Germany, Italy, Japan, Netherlands, New Zealand, Norway, Sweden, Switzerland, United Kingdom, United States. Iceland is dropped from our earlier sample because of missing data. For West Germany, changes are calculated over the period 1975-91 instead of 1975-97 then annualized.

2. Population growth is the annualized percentage change in population 15 to 64 . When estimating by IV, population growth over the period 1960-74 is used to instrument population growth over 1975-97.

3. GDP-60 is the level of real GDP per capita in 1960.

4. $\Delta$ Emp. rate is the annualized change in the employment rate over the period $75-97$.

5. In Rows (1) and (2), Finland, Netherlands and New Zealand are dropped from the sample because of missing data.

6. In Row (7), Denmark, Norway and Switzerland are dropped from the sample because of missing data.

7. In row (8), a dummy variable for Anglo-saxon countries and a dummy variable for Scandinavian countries is included in the regressions. 


\section{Appendix A}

In this appendix, we focus on the proofs of Lemmas related to the case with endogenous human capital accumulation, that is, Lemma 1A and Lemma 2A (and hence Proposition 1). We proceed as follows. We first begin by presenting the set of equations which characterize the Walrasian Equilibrium when the two technologies $F^{O}(\cdot)$ and $F^{M}(\cdot)$ are in use. Recall, that we are assuming the modern technology is sufficient efficient for it to be adopted in both the pre and post information revolution era. Moreover, since we are assuming that the modern technology is skill intensive $(\lambda>1)$ and that it doesn't use unskilled labor, it will necessarily be the case that the old technology always remains in use. Hence, it is appropriate to focus only on cases where both technologies are in use. After presenting this set of equations, we will state an intermediary Lemma (Lemma X1). Lemma X1 will highlight certain general features the Walrasian Equilibrium in our setting, that is, features that do not rely on the particular parameterization of technology given in (1) and (2)). Once we have proven Lemma X1, the proofs of Lemma $1 \mathrm{~A}$ and Lemma $2 \mathrm{~A}$ are rather straightforward.

- The Walrasian Equilibrium Conditions.

In order to present the Equilibrium Conditions explicitly, it is useful to work with unit cost functions instead of production functions. To this end, let $C^{O}\left(w, r_{H}, r_{K}\right)$ and $C^{M}\left(r_{H}, r_{I T}\right)$ represent the unit cost functions associated with respectively the old and modern processes of production. Moreover, let $Y^{O}$ and $Y^{M}$ represent the amount of the final good produced using the old and modern forms of production. At this point, we don't impose particular function forms on the cost functions (they need only be cost functions associated with CRS-convex technologies). Consider the following set of 13 equations in the 13 variables $\left\{w_{t}, r_{H, t}, r_{K, t}, r_{I T, t}, r_{t}\right\}$ and $\left\{L_{t}, H_{t}, K_{t}, I T_{t}, Y_{t}^{O}, Y_{t}^{M}, h_{t}, B_{t}\right\}$.

$$
\begin{gathered}
L_{t}=(1+\eta)^{t} \quad(A 1) \\
H_{t}=h_{t}(1+\eta)^{t} \quad(A 2) \\
Q^{\prime}\left(h_{t}\right)=r_{H, t} \quad(A 3) \\
B_{t+1}=\left(1+r_{t+1}\right)\left(\frac{1}{\beta^{\frac{-1}{\sigma}}\left(\frac{1+r_{t+1}}{1+\eta}\right)^{\frac{1-\sigma}{-\sigma}}+1}\right)\left(w_{t}+h r_{H, t}-Q(h)+\frac{B_{t}}{(1+\eta)}\right) \\
K_{t}+\frac{I T_{t}}{\theta}=\frac{B_{t}(1+\eta)^{t-1}}{\left(1+r_{t}\right)}
\end{gathered}
$$




$$
\begin{array}{rc}
r_{k, t}=\theta_{t} r_{I T, t}=1+r_{t} & (A 6),(A 7) \\
L_{t}=C_{1}^{O}\left(w_{t}, r_{H, t}, r_{K, t}\right) Y_{t}^{O} & (A 8) \\
H_{t}=C_{2}^{O}\left(w_{t}, r_{H, t}, r_{K, t}\right) Y_{t}^{O}+C_{1}^{M}\left(r_{H, t}, r_{I T, t}\right) Y_{t}^{M} \\
K_{t}=C_{3}^{O}\left(w_{t}, r_{H, t}, r_{K, t}\right) Y_{t}^{O} & (A 10) \\
I T_{t}=C_{2}^{M}\left(r_{H, t}, r_{I T, t}\right) Y_{t}^{M} & (A 11) \\
C^{O}\left(w_{t}, r_{H, t}, r_{K, t}\right)=1 & (A 12) \\
C^{M}\left(r_{H, t}, r_{I T, t}\right)=1 & (A 13)
\end{array}
$$

Equations (A1)-(A5) give the supply of factors by households, Equations (A8)-(A13) give the demand of factors by firms, and Equations (A6) and (A7) are the no-arbitrage conditions on the capital markets. Since the way we have set up this system of equation guaranties that supply equals demand in all the markets (by Walras' Law the goods market equilibrium condition is omitted), it thereby represents the Walrasian equilibrium of our model with endogenous human capital accumulation. Note that in the above equations, a subscript on the cost function represent the derivative with respect to the nth argument.

Since we will focus only the steady state, it is possible to simplify the above system into the following set of 7 equations in 7 variables $\left\{w, r_{H}, \tilde{r}\right\}$ and $\left\{\tilde{k}, \tilde{Y}^{O}, \tilde{Y}^{M}, h\right\}$.

$$
\begin{array}{r}
Q^{\prime}(h)=r_{H} \quad\left(A 1^{\prime}\right) \\
\tilde{k}=\frac{s}{(1+\eta)}\left(w+h r_{H}-Q(h)+\tilde{k} \tilde{r}\right)
\end{array}
$$

where $s=\frac{1}{\beta^{\frac{-1}{\sigma}}\left(\frac{\tilde{r}}{1+\eta}\right)^{\frac{1-\sigma}{-\sigma}}+1}$

$$
\begin{array}{rr}
1=C_{1}^{O}\left(w, r_{H}, \tilde{r}\right) \tilde{Y}^{O} & \left(A 3^{\prime}\right) \\
h=C_{2}^{O}\left(w, r_{H}, \tilde{r}\right) \tilde{Y}^{O}+C_{1}^{M}\left(r_{H}, \frac{\tilde{r}}{\theta}\right) \tilde{Y}^{M} \\
\tilde{k}=C_{3}^{O}\left(w, r_{H}, \tilde{r}\right) \tilde{Y}^{O}+\frac{C_{2}^{M}\left(r_{H}, \frac{\tilde{r}}{\theta}\right)}{\theta} \tilde{Y}_{t}^{M} \\
C^{O}\left(w, r_{H}, \tilde{r}\right)=1 & \left(A 6^{\prime}\right) \\
C^{M}\left(r_{H}, \frac{\tilde{r}}{\theta}\right)=1 & \left(A 7^{\prime}\right)
\end{array}
$$


where $\tilde{r}=r_{K}=r_{I T} \theta, \tilde{k}=\frac{K+\frac{I T}{\theta}}{(1+\eta)^{t}}$ is the per capital total capital stock, $\tilde{Y}^{O}=\frac{Y^{O}}{(1+\eta)^{t}}$ is the per capita production of output using the old technology and $\tilde{Y}^{M}=\frac{Y^{M}}{(1+\eta)^{t}}$ is the per capita production of output using the modern technology.

This modified system of equations, where quantities are all expressed in per capita terms, represents the two accumulation equations for human and physical capital and the factor market clearing conditions. Note that traditional and computer based capital can be aggregated into one variable $\tilde{k}$ using the relative price $\frac{1}{\theta}$.

We are now in a position to ask how population growth affects the steady state wage and output structure in this economy. A partial answer to this question is given by Lemma $\mathrm{X} 1$.

\section{Lemma X1:}

1) $\frac{\partial w}{\partial \eta}>0$ if and only if $\frac{C_{2}^{M}\left(r_{H}, \frac{\tilde{r}}{\theta}\right)}{C_{3}^{O}\left(w, r_{H}, \tilde{r}\right)}>\frac{C_{1}^{M}\left(r_{H}, \tilde{\frac{\tilde{r}}{\theta}}\right)}{C_{2}^{O}\left(w, r_{H}, \tilde{r}\right)}$

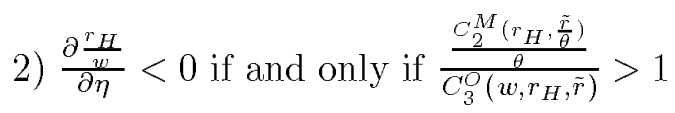

3a) $\frac{\partial \tilde{Y}^{M}}{\partial \eta}<0$ if $\frac{C_{2}^{M}\left(r_{H}, \tilde{\tilde{r}}\right)}{C_{3}^{O}\left(w, r_{H}, \tilde{r}\right)}>\frac{C_{1}^{M}\left(r_{H}, \tilde{\tilde{r}}\right)}{C_{2}^{O}\left(w, r_{H}, \tilde{r}\right)}$

3b) $\frac{\partial \tilde{Y}^{O}}{\partial \eta}<0$ if $\frac{C_{2}^{M}\left(r_{H}, \frac{\tilde{r}}{\theta}\right)}{C_{3}^{O}\left(w, r_{H}, \tilde{r}\right)}<\frac{C_{1}^{M}\left(r_{H}, \frac{\tilde{r}}{\theta}\right)}{C_{2}^{O}\left(w, r_{H}, \tilde{r}\right)}$

4) $\frac{\partial \tilde{r}}{\partial \eta}>0, \frac{\partial r_{H}}{\partial \eta}<0, \frac{\partial h}{\partial \eta}<0$

Proof of Lemma X1: The characterization given in Lemma X1 can be found by totally differentiating the system of equations ( $\left.\mathrm{A} 1^{\prime}\right)$ to (A7') and applying Cremer's rule. The only tedious aspect is to sign the determinant of the linearized system. To do so, it is helpful to use results presented in Diewert and Woodland (1977), which allows to uniquely sign the lower 5 by 5 matrix (this sub matrix corresponds to a system without factor accumulation). It is also easiest to first consider the case where $h$ is exogenous, since this allows one to temporarily drop Equation (A1'). Once the sign of the determinant is pinned down, the 
statements of Lemma X1 are easily inferred given the bloc diagonal aspect of the system and given that $\eta$ only enters one equation. For example, the effect of population growth on $r, r_{H}$ and $h$ are unambiguous, while the effect on $w$ can be seen to depend only on the sign of $\frac{C_{2}^{M}\left(r_{H}, \tilde{\tilde{r}}\right)}{\theta} \frac{C_{1}^{M}\left(r_{H}, \frac{\tilde{r}}{\theta}\right)}{C_{3}^{O}\left(w, r_{H}, \tilde{r}\right)}-\frac{C_{2}}{C_{2}^{O}\left(w, r_{H}, \tilde{r}\right)}$ as stated in the Lemma. Furthermore, the effects of population growth on the returns to education are seen to depend on the sign of $\frac{C_{2}^{M}\left(r_{H}, \tilde{r}\right)}{\theta} \frac{\theta}{C_{3}^{O}\left(w, r_{H}, \tilde{r}\right)}-1$. A step-by-step demonstration of this comparative static exercise is available from the authors.

The interesting aspect of Lemma X1 is that it shows that the effects of population growth depend on the relative factor intensities of the two underlying production technologies. In order to see this, it is helpful to recall that the derivative of the cost function with respect to a factor price is the factor requirement for producing one unit of output. Hence, statement 1 in Lemma X1 indicates that the effect of population growth on the price of unskilled labor depends on whether the modern technology uses more intensively capital (once properly normalized by the relative price $\theta$ to take account of the fact that the two technologies use different types of capital) or skill relative to that used in the older technology. Similarly, statement 3 indicates that the effect of population growth on the return to education depends on whether or not the modern technology uses more capital per unit of output(again appropriately normalized using the relative price) than the older technology. Hence, from Lemma X1 and our assumption that initially (before the information revolution) the relative capital intensity of the modern technology versus the old technology is greater that the skill intensity (which stated formally is equivalent to assuming that $\theta$ is low enough for $\left.\frac{C_{2}^{M}\left(r_{H}, \tilde{\frac{\tilde{\theta}}{\theta}}\right)}{C_{3}^{O}\left(w, r_{H}, \tilde{r}\right)}>\frac{C_{1}^{M}\left(r_{H}, \frac{\tilde{r}}{\theta}\right)}{C_{2}^{O}\left(w, r_{H}, \tilde{r}\right)}\right)^{52}$, we can immediately infer from Lemma X1 all the effects stated in Lemma $1 \mathrm{~A}$. In particular, we can infer the effect of population growth on the return to education since $\frac{C_{1}^{M}\left(r_{H}, \frac{\tilde{r}}{\theta}\right)}{C_{2}^{O}\left(w, r_{H}, \tilde{r}\right)}=\frac{1}{\lambda}>1$. The reason we can't immediately infer Lemma $2 \mathrm{~A}$ from Lemma $\mathrm{X} 1$ is that we need to know whether, for a sufficiently large increase in $\theta$ (starting from $\theta_{0}$ ), there will necessarily be a reversal in factor intensities in the sense that for sufficiently high values of $\theta, \frac{C_{2}^{M}\left(r_{H}, \tilde{\theta}\right)}{C_{3}^{O}\left(w, r_{H}, \tilde{r}\right)}<\frac{C_{1}^{M}\left(r_{H}, \tilde{\tau}\right)}{C_{2}^{O}\left(w, r_{H}, \tilde{r}\right)}$ and $\frac{C_{1}^{M}\left(r_{H}, \tilde{\frac{\tau}{\theta}}\right)}{C_{2}^{O}\left(w, r_{H}, \tilde{r}\right)}<1$. This is shown below using the parameterization of technology given by Equations (1) and (2).

\footnotetext{
${ }^{52} \mathrm{~A}$ reader may wonder whether this condition is consistent with the environment. In effect, as long as $\lambda$ is between $r_{h}^{*}+2\left(r^{*} w^{*}\right) \cdot 5<1$ and 1 (where starred variables are the factor prices that would prevail in the absence of the modern technology), there always exist a $\theta$ such that this condition is satisfied.
} 
Proof of Lemma 2A: Given Lemma X1, what needs to be shown to prove Lemma $2 \mathrm{~A}$ is that there exists a $\theta^{*}$, such that if the technologies of production satisfy Equations (1) and (2) of the text and if $\theta>\theta^{*}$, then

$$
\begin{gathered}
\frac{\frac{C_{2}^{M}\left(r_{H}, \tilde{r}\right)}{\theta}}{C_{3}^{O}\left(w, r_{H}, \tilde{r}\right)}<\frac{C_{1}^{M}\left(r_{H}, \frac{\tilde{r}}{\theta}\right)}{C_{2}^{O}\left(w, r_{H}, \tilde{r}\right)} \\
\frac{\left.\frac{C_{2}^{M}\left(r_{H}, \tilde{r}\right)}{\theta}\right)}{C_{3}^{O}\left(w, r_{H}, \tilde{r}\right)}<1
\end{gathered}
$$

In effect, given that $\lambda<1$ and that $\frac{C_{1}^{M}}{C_{2}^{O}}=\frac{1}{\lambda}$, we need only focus on the second condition since it implies the first condition. To show the existence of this $\theta^{*}$, it is useful to begin by stating Equations (A3') to (A7') explicitly for the case at hand (Equations (A1') and (A2') remain unchanged).

$$
\begin{gathered}
1=\left(\frac{\tilde{r}}{w}\right)^{5} \tilde{Y}^{O} \quad\left(A 3^{\prime \prime}\right) \\
h=\tilde{Y}^{O}+\frac{\tilde{Y}^{M}}{\lambda} \quad\left(A 4^{\prime \prime}\right) \\
\tilde{K}=\left(\frac{w}{\tilde{r}}\right)^{5} \tilde{Y}^{O}+\frac{\tilde{Y}_{t}^{M}}{\theta} \quad\left(A 5^{\prime \prime}\right) \\
2 w^{.5} \tilde{r}^{.5}+r_{H}=1 \quad\left(A 6^{\prime \prime}\right) \\
\frac{\tilde{r}}{\theta}+\frac{r H}{\lambda}=1 \quad\left(A 7^{\prime \prime}\right)
\end{gathered}
$$

Although the entire solution to this system of equations cannot be stated explicitly, the non-explicit component can be reduced to a system of two equations in the two unknowns $h, \tilde{k}: 53$

$$
Q^{\prime}(h)=\lambda\left(1-\frac{1-\lambda}{2 \theta\left(\frac{\lambda^{2}}{4 \theta^{2}}+\tilde{k}-\frac{\lambda h}{\theta}\right)^{5}}\right)
$$

\footnotetext{
${ }^{53}$ In the case where $\sigma=1$ and therefore the savings rate is constant, we can solve explicitly for $k$ since it is the solution to a quadratic equation. In this case, solving our initial system of 13 equations is reduced to solving one non-linear equation in the one unknown $h$.
} 


$$
\tilde{k}=\left(\frac{\frac{1}{1+\eta}}{\beta^{\frac{-1}{\sigma}}\left(\frac{\tilde{r}}{1+\eta}\right)^{\frac{1-\sigma}{-\sigma}}+1}\right)\left(\lambda h+\frac{(1-\lambda) \lambda}{2 \theta}+(1-\lambda)\left(\frac{\lambda^{2}}{4 \theta^{2}}+\tilde{k}-\frac{\lambda h}{\theta}\right)^{.5}-Q(h)\right)
$$

where $\tilde{r}$ is explicitly is explicitly given by

$$
\tilde{r}=\frac{1-\lambda}{2\left(\frac{\lambda^{2}}{4 \theta^{2}}+\tilde{k}-\frac{\lambda h}{\theta}\right)^{5}}
$$

Furthermore, $r_{H}, w$ and total production $\tilde{Y}^{O}+\tilde{Y}^{M}$ are given by

$$
\begin{gathered}
r_{H}=\lambda\left(1-\frac{\tilde{r}}{\theta}\right) \\
w=\left(\frac{1-\lambda}{2 \tilde{r}}+\frac{\lambda}{2 \theta}\right)^{2} \tilde{r} \\
\tilde{Y}^{O}+\tilde{Y}^{M}=\lambda h+\frac{(1-\lambda) \lambda}{2 \theta}+(1-\lambda)\left(\frac{\lambda^{2}}{4 \theta^{2}}+\tilde{k}-\frac{\lambda h}{\theta}\right)^{5}
\end{gathered}
$$

Let us now focus on showing that, for $\theta$ s sufficiently large, $\frac{C_{2}^{M}\left(r_{H}, \tilde{r}\right)}{C_{3}^{O}\left(w, r_{H}, \tilde{r}\right)}<1$. Note that this conditions corresponds (for our parameterization of the cost functions) to showing that for $\theta$ s sufficiently large:

$$
\frac{1}{\theta\left(\frac{w}{\tilde{r}}\right)^{.5}}<1
$$

In order to see that the above condition will be satisfied when $\theta$ is sufficiently large, consider the limit of the LHS of this expression as $\theta$ goes to infinity. Using the solutions for $w$ and $\tilde{r}$, it is easy to verify that this limit take the following simple form.

$$
\frac{1}{\theta \tilde{k}}
$$

Therefore, unless $\tilde{k}$ goes to zero as $\theta$ goes to infinity, the above limit will go to zero as $\theta$ goes to infinity and hence for $\theta$ sufficiently large it will necessarily be the case that $\frac{1}{\theta\left(\frac{w}{\tilde{r}}\right)^{.5}}<1$. In order to see that $\tilde{k}$ does not go to zero as $\theta$ goes to infinity, note that $h$ will converge to $\bar{h}$ defined by $Q^{\prime}(\bar{h})=\lambda$, and that the accumulation equation for $\tilde{k}$ will become:

$$
\tilde{k}=\frac{s(\tilde{k})}{1+\eta}\left(\left(Q^{\prime}(\bar{h}) \bar{h}-Q(\bar{h})+(1-\lambda) \tilde{k}^{.5}\right)\right.
$$


where $s(\tilde{k})=1-\frac{1}{\beta^{\frac{1}{\sigma}}\left(\frac{1-\lambda}{2(1+\eta) \tilde{k}^{-5}}\right)^{\frac{1-\sigma}{\sigma}}+1}$. Since $h$ is optimality chosen, it is necessarily the case that $Q^{\prime}(\bar{h}) \bar{h}-Q(\bar{h})>0$. Therefore, given that the above limit accumulation equation for $\tilde{k}$ is a rather standard and well behaved accumulation equation, it is straightforward to verify that $\tilde{k}$ will remain strictly above zero as $\theta$ goes to infinity. Hence, this proves that there exists a $\theta^{*}$ such that if $\theta>\theta^{*}$, by Lemma X1 we have, $\frac{\partial w}{\partial \eta}<0, \frac{\partial \frac{r_{H}}{\partial \eta}}{\partial \eta}>0, \frac{\partial \tilde{Y}^{O}}{\partial \eta}<0, \frac{\partial \tilde{r}}{\partial \eta}<0$ ,$\frac{\partial r_{H}}{\partial \eta}>0$ as stated in Lemma $2 \mathrm{~A}$.

\section{Appendix B}

In this appendix, we prove Lemma 1B and Lemma 2B (and hence Proposition 2) in a manner very similar to that presented in Appendix A to prove Lemmas 1A and 1B. Hence, Appendix 1A should be read before this appendix.

\section{- The Walrasian Equilibrium Conditions}

The Equilibrium Conditions for the case with variable labor supply are given below where an $i$ subscript denote the type of individuals, that is, $i=1$ corresponds to individuals which acquire no education $\left(h_{1}=0\right)$ and $i=2$ individual correspond to individuals who's educational attainment is associated with $h_{2}>0$ units of human capital per time unit supplied to the market. The equilibrium set of 17 equations in the 17 variables $\left\{w_{t}, r_{H, t}, r_{K, t}, r_{I T, t}, r_{t}\right\}$ and $\left\{L_{t}, H_{t}, K_{t}, I T_{t}, Y_{t}^{O}, Y_{t}^{M}, l_{i, t}, s_{i, t}, B_{i, t}\right\}$ are:

$$
\begin{gathered}
L_{t}=(1+\eta)^{t}\left(\pi l_{1, t}+(1-\pi) l_{2, t}\right) \\
H_{t}=(1+\eta)^{t}(1-\pi) l_{2, t} h_{2} \quad(B 1) \\
\alpha D_{0}\left(1-l_{i, t}\right)^{\alpha-1}=1+\frac{r_{H, t}}{w} h_{i} \quad(B 3, B 4) \\
B_{i, t+1}=\left(1+r_{t+1}\right)\left(\frac{1}{\beta^{\frac{-1}{\sigma}}\left(\frac{1+r}{1+\eta}\right)^{\frac{1-\sigma}{-\sigma}}+1}\right)\left(w_{t}\left(l_{i, t}-s_{i, t}\right)+l_{i, t} h_{i} r_{H, t}+\frac{B_{i, t}}{(1+\eta)}\right) \\
K_{t}+\frac{I T_{t}}{\theta}=\frac{\left(\pi B_{1, t}+(1-\pi) B_{2, t}\right)(1+\eta)^{t-1}}{\left(1+r_{t}\right)} \\
s_{i, t}=\bar{d}-D_{o}\left(1-l_{i, t}\right) \quad(B 8),(B 9)
\end{gathered}
$$




$$
\begin{array}{r}
r_{k, t}=\theta_{t} r_{I T, t}=1+r_{t} \quad(B 10),(B 11) \\
L_{t}=C_{1}^{O}\left(w_{t}, r_{H, t}, r_{K, t}\right) Y_{t}^{O}+(1+\eta)^{t}\left(\pi s_{1, t}+(1-\pi) s_{2, t}\right) \\
H_{t}=C_{2}^{O}\left(w_{t}, r_{H, t}, r_{K, t}\right) Y_{t}^{O}+C_{1}^{M}\left(r_{H, t}, r_{T T, t}\right) Y_{t}^{M} \\
K_{t}=C_{3}^{O}\left(w_{t}, r_{H, t}, r_{K, t}\right) Y_{t}^{O} \\
I T_{t}=C_{2}^{M}\left(r_{H, t}, r_{I T, t}\right) Y_{t}^{M} \\
C^{O}\left(w_{t}, r_{H, t}, r_{K, t}\right)=1 \\
C^{M}\left(r_{H, t}, r_{I T, t}\right)=1
\end{array}
$$

Equations (B1)-(B6) give the supply of factors by households, Equations (B12)-(B17) give the demand of factors by firms, Equations (B8)-(B9) give the demand for services by households and Equations (B10) and (B11) are the no-arbitrage conditions on the capital markets. Since this system of equation guaranties that supply equals demand in all the markets (by Walras' Law the goods market equilibrium condition is omitted), it thereby represents the Walrasian equilibrium of our model with variable labour supply. In order to reduce the steady state of the above system of equations to a set similar to that given by Equations (A1')-(A7') in Appendix A, it is helpful to redefine the following variables: let $\tilde{k}=\frac{K+\frac{I T}{\theta}}{(1+\eta)^{t}\left(\pi\left(l_{1}-s_{1}\right)+(1-\pi)\left(l_{2}-s_{2}\right)\right)}$ be the total capital stock per hour worked excluding services, $\tilde{Y}^{O}=\frac{Y^{O}}{(1+\eta)^{t}\left(\pi\left(l_{1}-s_{1}\right)+(1-\pi)\left(l_{2}-s_{2}\right)\right)}$ is the production of output using the old technology per hour worked excluding services, $\tilde{Y}^{M}=\frac{Y^{M}}{(1+\eta)^{t}\left(\pi\left(l_{1}-s_{2}\right)+(1-\pi)\left(l_{2}-s_{2}\right)\right)}$ is the production of output using the modern technology per hour worked excluding services and finally $\tilde{h}=\frac{(1-\pi) h_{2} l_{2}}{\left(\pi\left(l_{1}-s_{1}\right)+(1-\pi)\left(l_{2}-s_{2}\right)\right.}$ is the human capital per hour worked excluding services. With this notation, it is possible to reduce the above system into the following set of 8 simultaneous equations in 8 variables $\left\{w, r_{H}, \tilde{r}\right\}$ and $\left\{\tilde{k}, \tilde{Y}^{O}, \tilde{Y}^{M}, \tilde{h}, l_{2}\right\}$. Note that the variable $l_{1}$ and $s_{1}$ can be treated as constants in this reduced system since there are determined exclusively be Equations (B3) and (B8) and therefore are invariant to changes in $\eta$. Furthermore, the level of services consumed by agents of type $i=2\left(s_{2}\right)$ does not need to be included in the system since it is simply given by Equation (B9) once $l_{2}$ is determined.

$$
\begin{gathered}
\alpha D_{0}\left(1-l_{2, t}\right)^{\alpha-1}=1+\frac{r_{H, t}}{w} h_{2} \quad\left(B 1^{\prime}\right) \\
\tilde{h}=\frac{(1-\pi) h_{2} l_{2}}{\left(\pi\left(l_{1}-s_{1}\right)+(1-\pi)\left(l_{2}-\bar{d}+D_{0}\left(1-l_{2}\right)^{\alpha}\right)\right.}
\end{gathered}
$$




$$
\tilde{k}=\frac{s}{(1+\eta)}\left(w+h r_{H}+\tilde{k} \tilde{r}\right)
$$

where $s=\left(\frac{1}{\beta^{\frac{-1}{\sigma}}\left(\frac{\tilde{r}}{1+\eta}\right)^{\frac{1-\sigma}{-\sigma}}+1}\right)$

$$
\begin{array}{rr}
1=C_{1}^{O}\left(w, r_{H}, \tilde{r}\right) \tilde{Y}^{O} & \left(B 4^{\prime}\right) \\
h=C_{2}^{O}\left(w, r_{H}, \tilde{r}\right) \tilde{Y}^{O}+C_{1}^{M}\left(r_{H}, \frac{\tilde{r}}{\theta}\right) \tilde{Y}^{M} \\
\tilde{k}=C_{3}^{O}\left(w, r_{H}, \tilde{r}\right) \tilde{Y}^{O}+\frac{C_{2}^{M}\left(r_{H}, \frac{\tilde{r}}{\theta}\right)}{\theta} \tilde{Y}_{t}^{M} \\
C^{O}\left(w, r_{H}, \tilde{r}\right)=1 \quad\left(B 7^{\prime}\right) \\
C^{M}\left(r_{H}, \frac{\tilde{r}}{\theta}\right)=1 \quad\left(B 8^{\prime}\right)
\end{array}
$$

There are two aspects to note about this reduced system of equations. First, Equations (B1') and (B2') can be seen as representing one equation that determines $\tilde{h}$ as a function of $\frac{r_{h}}{w}$. In this sense (B1') and (B2') are very similar to Equation (A1') except that $\tilde{h}$ is determined by the return to education while $h$ was determined by the price of human capital. Second, note that Equations (B3') to (B8') are identical in form to Equations $\left(\mathrm{A} 2^{\prime}\right)$-(A7'). Hence, it is should not be surprising that this system of equations gives similar comparative static results to those presented in Appendix A. In particular, we can state these comparative static results in Lemma X2.

Lemma X1: If $\alpha$ is not too large,

1) $\frac{\partial w}{\partial \eta}>0$ if and only if $\frac{C_{2}^{M}\left(r_{H}, \tilde{\tilde{r}}\right)}{\theta} \frac{C_{1}^{M}\left(r_{H}, \tilde{\tau}\right)}{C_{3}^{O}\left(w, r_{H}, \tilde{r}\right)}>\frac{\tilde{r}}{C_{2}^{O}\left(w, r_{H}, \tilde{r}\right)}$

2) $\frac{\partial \frac{r_{H}}{w \eta}}{\partial \eta}<0, \frac{\partial l_{2}}{\partial \eta}<0, \frac{\partial s_{2}}{\partial \eta}<0$ if and only if $\frac{C_{2}^{M}\left(r_{H}, \frac{\tilde{r}}{\theta}\right)}{C_{3}^{O}\left(w, r_{H}, \tilde{r}\right)}>1$

3a) $\frac{\partial \frac{Y^{M}}{L}}{\partial \eta}<0$ if $\frac{C_{2}^{M}\left(r_{H}, \frac{\tilde{r}}{\theta}\right)}{C_{3}^{O}\left(w, r_{H}, \tilde{r}\right)}>\frac{C_{1}^{M}\left(r_{H}, \tilde{\tilde{r}}\right)}{C_{2}^{O}\left(w, r_{H}, \tilde{r}\right)}$

3b) $\frac{\partial \frac{Y^{O}}{\partial}}{\partial \eta}<0$ if $\frac{C_{2}^{M}\left(r_{H}, \tilde{\tilde{r}}\right)}{C_{3}^{O}\left(w, r_{H}, \tilde{r}\right)}<\frac{C_{1}^{M}\left(r_{H}, \frac{\tilde{\theta}}{\theta}\right)}{C_{2}^{O}\left(w, r_{H}, \tilde{r}\right)}$ 
4) $\frac{\partial \tilde{r}}{\partial \eta}>0, \frac{\partial r_{H}}{\partial \eta}<0$

5) All the above comparative effects increase in absolute value as $\alpha$ increases. iff

$$
\frac{\frac{C_{2}^{M}\left(r_{H}, \tilde{r}\right)}{\theta}}{C_{3}^{O}\left(w, r_{H}, \tilde{r}\right)}<1
$$

Proof of Lemma X1: The characterization given in Lemma X2 can be found by totally differentiating the system of equations (B1') to (B8') and applying Cremer's rule. The only major difference with the system of equations given by (A1')-(A7') is that the sign the determinant of the linearized system is now not unambiguous as is can depend on the size of $\alpha$. In particular, if $\frac{C_{2}^{M}\left(r_{H}, \frac{\tilde{r}}{\theta}\right)}{C_{3}^{O}\left(w, r_{H}, \tilde{r}\right)}<1$, then the determinant switches sign when $\alpha$ is sufficiently large. As we discussed in the text, we therefore focus only on the case where $\alpha$ is not too large, that is, the case where the determinant remains the same sign as was the case for the system $\left(\mathrm{A} 1^{\prime}\right)-\left(\mathrm{A} 7^{\prime}\right)$. In effect, this appears to be the most natural case since it always implies that higher $\eta$ is associated with a higher interest rate. Once the sign of the determinant is pinned down, the statements of Lemma X2 are easily inferred given the bloc diagonal aspect of the system and given that $\eta$ only enters one equation. In particular, statement (4) in Lemma X2 is implied by the fact that determinant of the linearized system depends on $\alpha$, while the numerators of these derivatives do not depend on $\alpha$. Once again, a step-by-step demonstration of this comparative static exercise is available from the authors.

¿From Lemma X2, all the elements of Lemma 1B that are in common with Lemma $1 \mathrm{~A}$ can be directly inferred since we have assumed that in the pre-information revolution era $\theta$ is low enough for it to be the case that $\frac{C_{2}^{M}\left(r_{H}, \tilde{r}\right)}{C_{3}^{O}\left(w, r_{H}, \tilde{r}\right)}>\frac{1}{\lambda}>1$. In order to prove the additional two elements of Lemma $1 \mathrm{~B}$, let us note that the employment rate for the economy is given by $\pi l_{1}+(1-\pi) l_{2}$ and that the fraction of employment in the service sector is given by $\frac{\pi s_{1}+(1-\pi) s_{2}}{\pi l_{1}+(1-\pi) l_{2}}$. It is therefore again immediate from Lemma $\mathrm{X} 2$ that an increase in $\eta$ will be associated with a lower employment rate in the pre-information revolution period and a lower per capita level of employment in services. It is of interest to also note that an increase in $\eta$ also implies a lower fraction of employment in the service sector in the pre-information revolution era since the denominator of the derivative of this fraction is equal to:

$$
\left((1-\pi) D^{\prime}\left(1-l_{2}\right)\left(\pi l_{1}+(1-\pi) l_{2}-(1-\pi)\left(\pi s_{1}+(1-\pi) s-2\right)\right) \frac{\partial l_{2}}{\partial \eta}\right.
$$


which is necessarily smaller than $(1-\pi)\left(\pi l_{1}+(1-\pi) l_{2}\right)\left(\alpha\left(1-l_{2}\right)^{\alpha-1}-1\right) \frac{\partial l_{2}}{\eta}$, which in turn is necessarily negative since condition (B1') implies that $\alpha\left(1-l_{2}\right)^{\alpha-1}-1$ is positive. Hence, this completes the proof of Lemma 1B. Once again, we can't immediately infer Lemma 2B from Lemma X2 since we need to know whether, for a sufficiently large increase in $\theta$ (starting from $\theta_{0}$ ), there will necessarily be a reversal in factor intensities in the sense that for sufficiently high values of $\theta, \frac{C_{2}^{M}\left(r_{H}, \tilde{\tilde{r}}\right)}{\theta} \frac{C_{1}^{M}\left(r_{H}, \tilde{r}\right)}{C_{3}^{O}\left(w, r_{H}, \tilde{r}\right)}<\frac{C_{1}^{M}\left(r_{H}, \tilde{r}\right)}{C_{2}^{O}\left(w, r_{H}, \tilde{r}\right)}<1$. This is shown, along the same lines as the proof of Lemma $2 \AA$, using the parameterization of technology given by Equations (1) and (2).

Proof of Lemma 2B: Given Lemma X2, what needs to be shown to prove Lemma 2B is that there exists a $\theta^{* *}$, such that if the technologies of production satisfy Equations (1) and (2) of the text and if $\theta>\theta^{* *}$, then

$$
\frac{\frac{C_{2}^{M}\left(r_{H}, \tilde{r}\right)}{\theta}}{C_{3}^{O}\left(w, r_{H}, \tilde{r}\right)}<1
$$

and hence

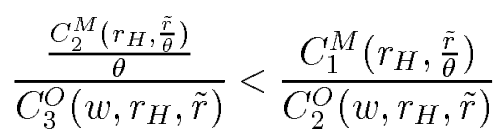

To show the existence of this $\theta^{*}$, we can proceed as in the proof of Lemma $2 \mathrm{~A}$ and note that the condition $\frac{C_{2}^{M}\left(r_{H}, \tilde{r}\right)}{C_{3}^{O}\left(w, r_{H}, \tilde{r}\right)}<1$ can be stated as follows (for our parameterization of the cost functions) :

$$
\frac{1}{\theta\left(\frac{w}{\tilde{r}}\right)^{.5}}<1
$$

Furthermore, the limit of the LHS of this expression as $\theta$ goes to infinity is again given by

$$
\frac{1}{\theta \tilde{k}}
$$

Since the accumulation equation for capital is in the limit given by

$$
\tilde{k}=\frac{s(\tilde{k})}{1+\eta}\left(\left(\lambda \tilde{h}+(1-\lambda) \tilde{k}^{.5}\right)\right.
$$

where $s(\tilde{k})=1-\frac{1}{\beta^{\frac{1}{\sigma}}\left(\frac{1-\lambda}{2(1+\eta) \tilde{k}^{5}}\right)^{\frac{1-\sigma}{-\sigma}}+1}$. and since $\tilde{h}$ is non-negative, $\tilde{k}$ will remain strictly above zero as $\theta$ goes to infinity. Hence, this proves that there exists a $\theta^{* *}$ such that if $\theta>\theta^{* *}$, and hence by lemma X2 we have 


$$
\frac{\partial w}{\partial \eta}<0, \frac{\partial \frac{r_{H}}{\partial \eta}}{\partial \eta}>0, \frac{\partial l_{2}}{\partial \eta}>0, \frac{\partial s_{2}}{\partial \eta}>0, \frac{\partial \frac{Y^{O}}{L}}{\partial \eta}<0, \frac{\partial \tilde{r}}{\partial \eta}<0, \frac{\partial r_{H}}{\partial \eta}>0
$$

Furthermore, by the same reasoning used in the proof of Lemma 1B, we have that an increase in $\eta$ is associate with a higher rate of employment and a higher per capital level of of employment in the service sector. • 


\section{References}

1. Daron Acemoglu Why Do New Technologies Complement Skills? Directed Technical Change and Wage Inequality, Quarterly Journal of Economics, November 1998 (A), 1055-1089.

2. Daron Acemoglu Changes in Unemployment and Wage Inequality: An Alternative Theory and Some Evidence, American Economic Review, December 1999, 1259-1278.

3. Basu, Susanto and David Weil Appropriate Technology and Growth, Quarterly Journal of Economics, 113(4), November 1998: 1025-54.

4. Paul Beaudry and David Green, What is Driving US and Canadian Wages: Endogenous Technical Change or Endogenous Choice of Technique?, N.B.E.R. working Paper 6853, December 1998.

5. Paul Beaudry and David Green, The Changing Structure of Wages in the US and Germany: What Explains the Difference?, N.B.E.R. working Paper 7697, May 2000.

6. Eli Berman, John Bound and Stephen Machin, Implications of Skilled-biased Technological Change: International Evidence, Quarterly Journal of Economics, November 1998, 1245-1280.

7. Olivier Blanchard, The Medium Run, Brookings Paper on Economic Activity, 1997.

8. Timothy F. Bresnahan, Erik Brynjolfson, Lorin M. Hitt, Information Technology, Workplace Organization and the Demand for Skilled Labor: Firm-Level Evidence, NBER working paper 7136, May 1999.

9. John Bound and George Johnson, Changes in the Structure of Wages in the 1980's: An Evaluation of Alternative Explanations, American Economic Review 77 (1992), 371-392.

10. David Card, Francis Kramarz and Thomas Lemieux Changes in the Structure of Wages and Employment: a comparison of the United States, Canada and France, Canadian Journal of Economics, 32, August 1999, 843-877.

11. David Card and W. Craig Riddell Unemployment in Canada and the United States: A Further Analysis, in B.C. Eaton and R.G. Harris, Trade, Technology and Economics: Essays in Honour of Richard G. Lipsey. Cheltenham, UK: Elgar, 1997, 4787.

12. Francesco Caselli, Technological Revolutions, American Economic Review, March 1999, $78-102$. 
13. Erwin Diewert and Allan Woodland Frank Knight's Theorem in Linear Programming Revisited, Econometrica 45 (1977), 375-398.

14. Duranton, Gilles, The Economics of Productive Systems: Segmentation and Skill-Biased Change, Working Paper, February 1998, London School of Economics.

15. Flug, Karnit and Zvi Hercowitz, Equipment Investment and Relative Demand for Skilled Labor, Review of Economic Dynamics, 2000.

16. Richard Freeman and Ronald Schettakat Low Wage Sevices: Interpreting the USGerman Difference, N.B.E.R. working paper 7611, March 2000.

17. Goldin, Claudia and Laurence Katz, The Origines of Technology-Skill Complementarity, Quarterly Journal of Economics 113, 1998, 693-732.

18. Goldin, Claudia and Lawrence Katz, The Returns to Skill in the United States Across the Twentieth Century, Nation Bureau of Economic Research Working Paper no. 7126, May 1999.

19. Amanda Gosling, Stephen Machin and Costas Meghir, The Changing Distribution of Male Wages in the UK, Institute for Fiscal Studies Mimeo, 1998.

20. Robert Gordon The Measurement of Durable Good Prices, University of Chicago Press, 1900.

21. Peter Gottschalk and Timothy M. Smeeding, Cross-National Comparison of Earnings and Income Inequality, Journal of Economic Literature, no. 2, vol. XXXV (1997), 633687.

22. Jeremy Greenwood, Zvi Hercowitz and Per Kursell, Long-Run Implications of Investment-Specific Technological Change, American Economic Review, 87, (1997), 341362.

23. Jeremy Greenwood, and Boyan Jovanovic, The IT Revolution and the Stock Market, American Economic Review Paper and proceedings, 89:116-122, May 1999.

24. Jeremey Greenwood and Mehmet Yorukoglu 1974, Cargegie Rochester Conference Series on Public Policy, 46, 1997.

25. James Heckman, L. Lochner and C. Taber Explaining Rising Wage Inequality: Explorations with a Dynamic General Equilibrium Model of Labor Earnings with Heterogenous Agents, Review of Economic Dynamics, 1(1), 1998. 
26. Chinhui Juhn, Kevin M. Murphy, and Brooks Pierce, Wage Inequality and the Rise in Returns to Skill, Journal of Political Economy 101 (1993), 410-442.

27. Dale W. Jorgenson and Eric Yip Whatever Happened to Productivity Growth, mimeo Harvard University, June 1999.

28. Dale W. Jorgenson and Kevin J. Stiroh Information Technology and Growth, American Economic Review, May (1999), 10915.

29. Lawrence F. Katz and Kevin M. Murphy, Changes in Relative Wages, 1963-1987: Supply and Demand Factors, Quarterly Journal of Economics, February (1992), 35-78.

30. Michael Kileyl, The Supply of Skilled Labor and Skilled Biased Technological Progress, Economic Journal, 1999.

31. Alan B. Kruger and Jorn-Steffen Pischke, Observations and Conjectures on the US Employment Miricle, N.B.E.R. working paper 6146, August 1997.

32. Per Krusell, Lee E. Ohanian, Jose - Victor Rios-Rull, and Giovanni L. Violante CapitalSkill Complementarity and Inequality: A Macroeconomic Analysis, Econometrica 2000.

33. Lee, David S. Wage Inequality in the US During the 1980s: Rising Dispersion or Falling Minimum Wage?, Quarterly Journal of Economics 114 (1999), 941-1024.

34. Thomas MaCurdy and Thomas Mroz, Measuring Macroeconomic Shifts in Wages from Cohort Specifications, working paper, (1995).

35. Obstfeld, Maurice and Kenneth Rogoff, The Six Major Puzzles in International Macroeconomics: Is Ther a Common Cause, NBER Macroeconomics Annual 2000, Ben Bernanke and Kenneth Rogoff (eds).

36. John Schmidt, The Changing Structure of Male Earnings in Britain, 1974-88 in R.B. Freeman and L.F. Katz, eds, Differences and Changes in Wage Structures. NBER. Chicago: University of Chicago Press, 1995, 177204.

37. Solow, Robert, A Contribution to the Theory of Economic Growth, Quaterly Journal of Economics, 70, 1956, 65-94.

38. Zeira, Joseph, Workers, Machines and Economic Growth, Quarterly Journal of Economics, 113(4), 1998, 1091-1118. 


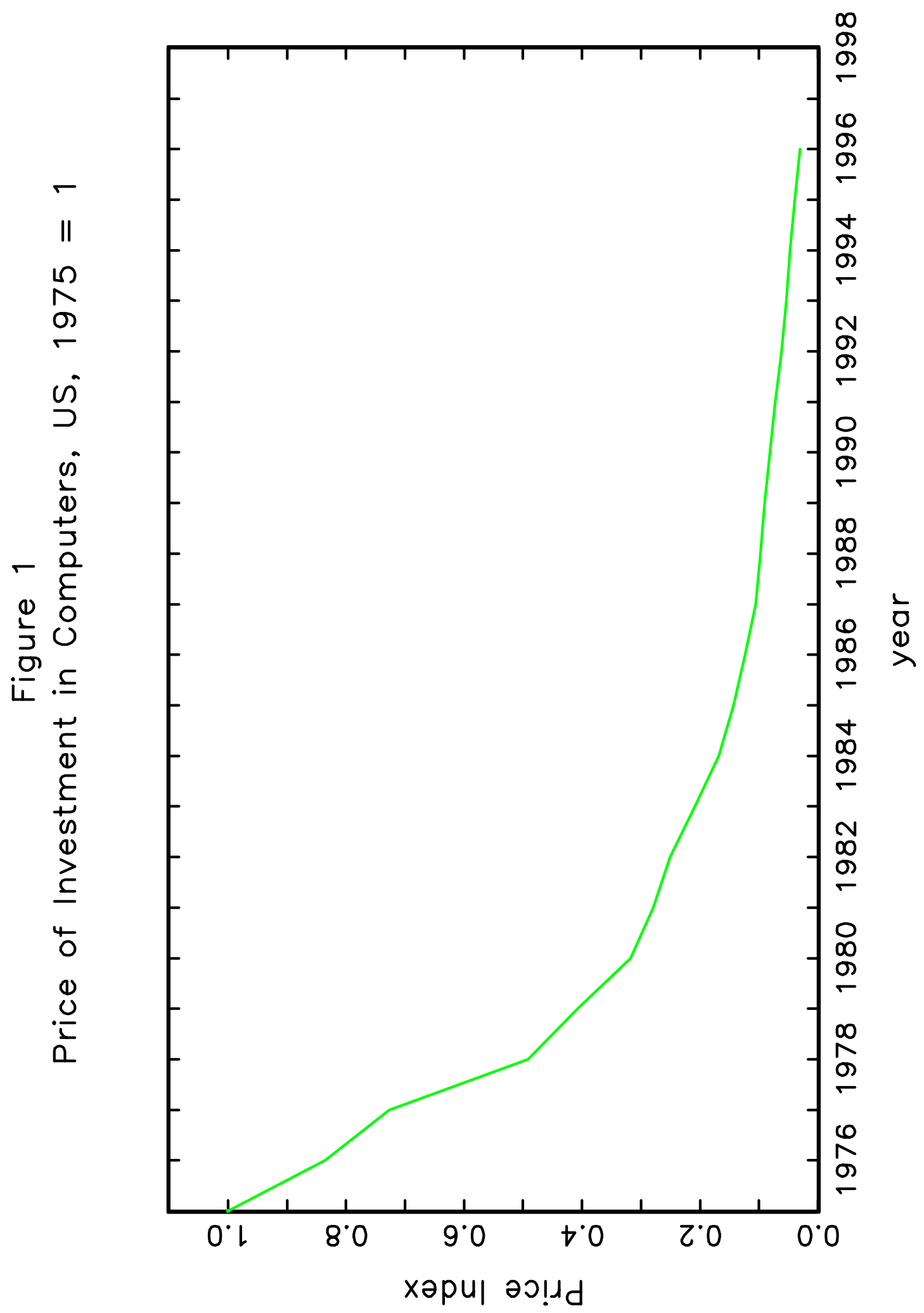



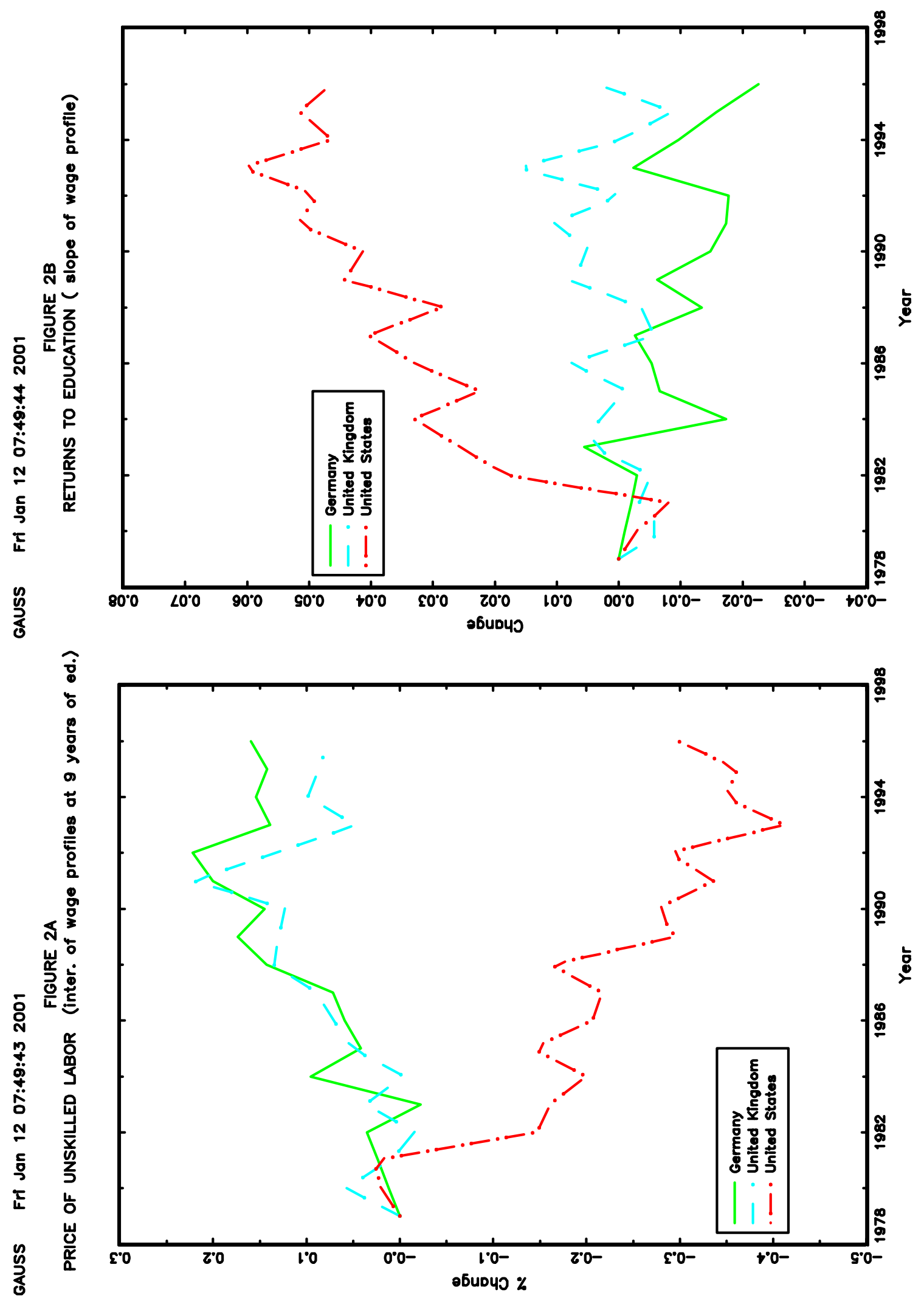

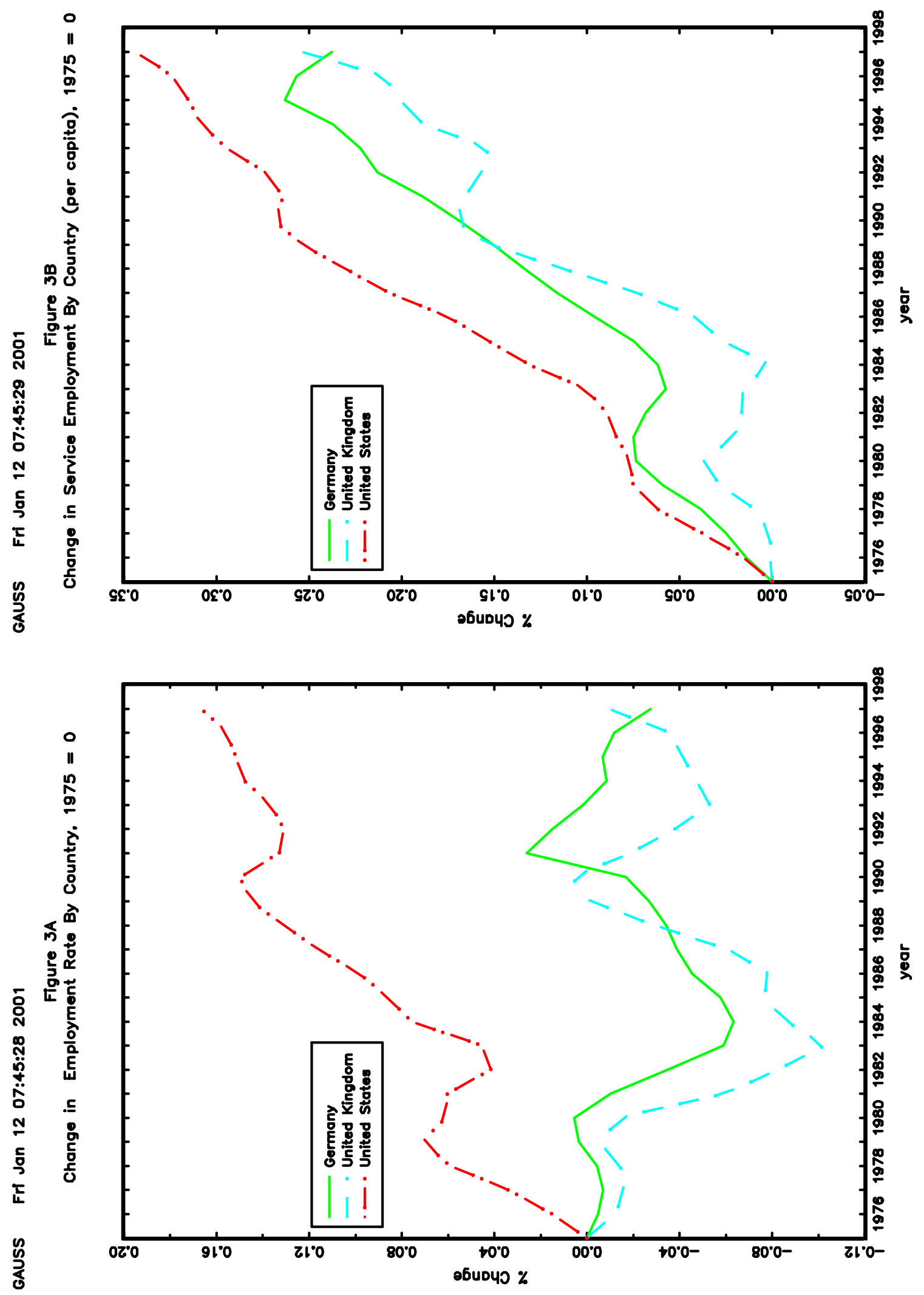


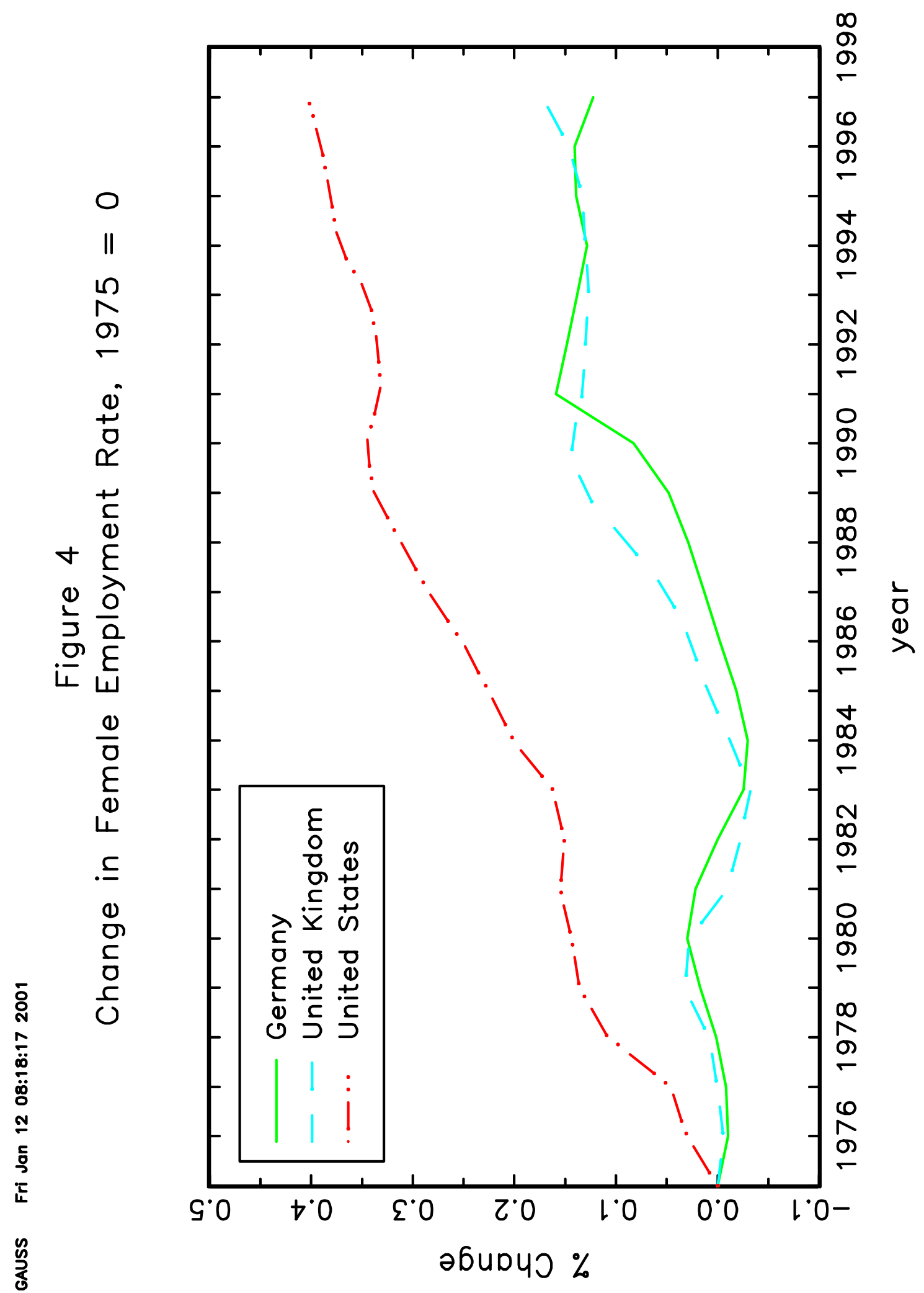



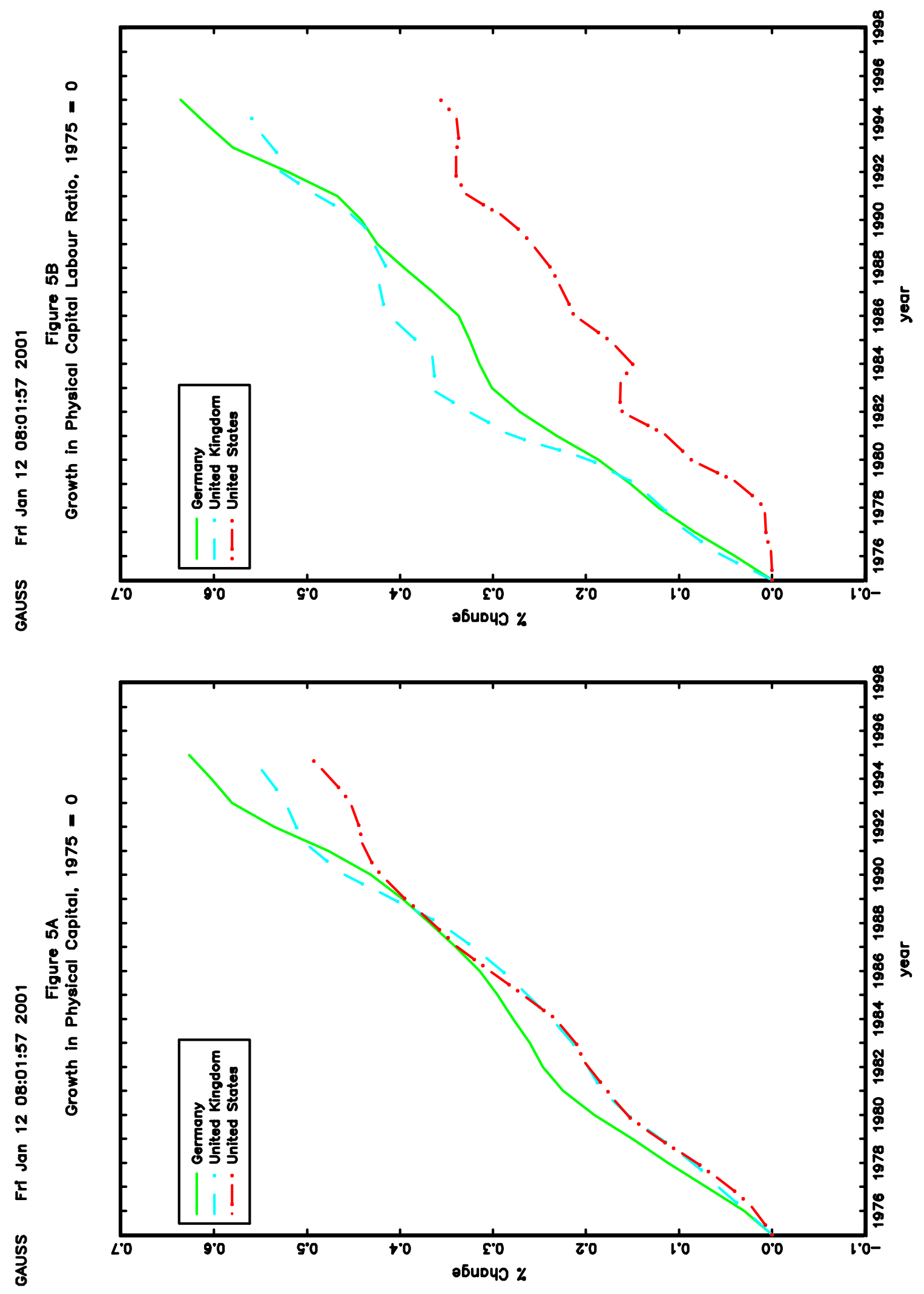

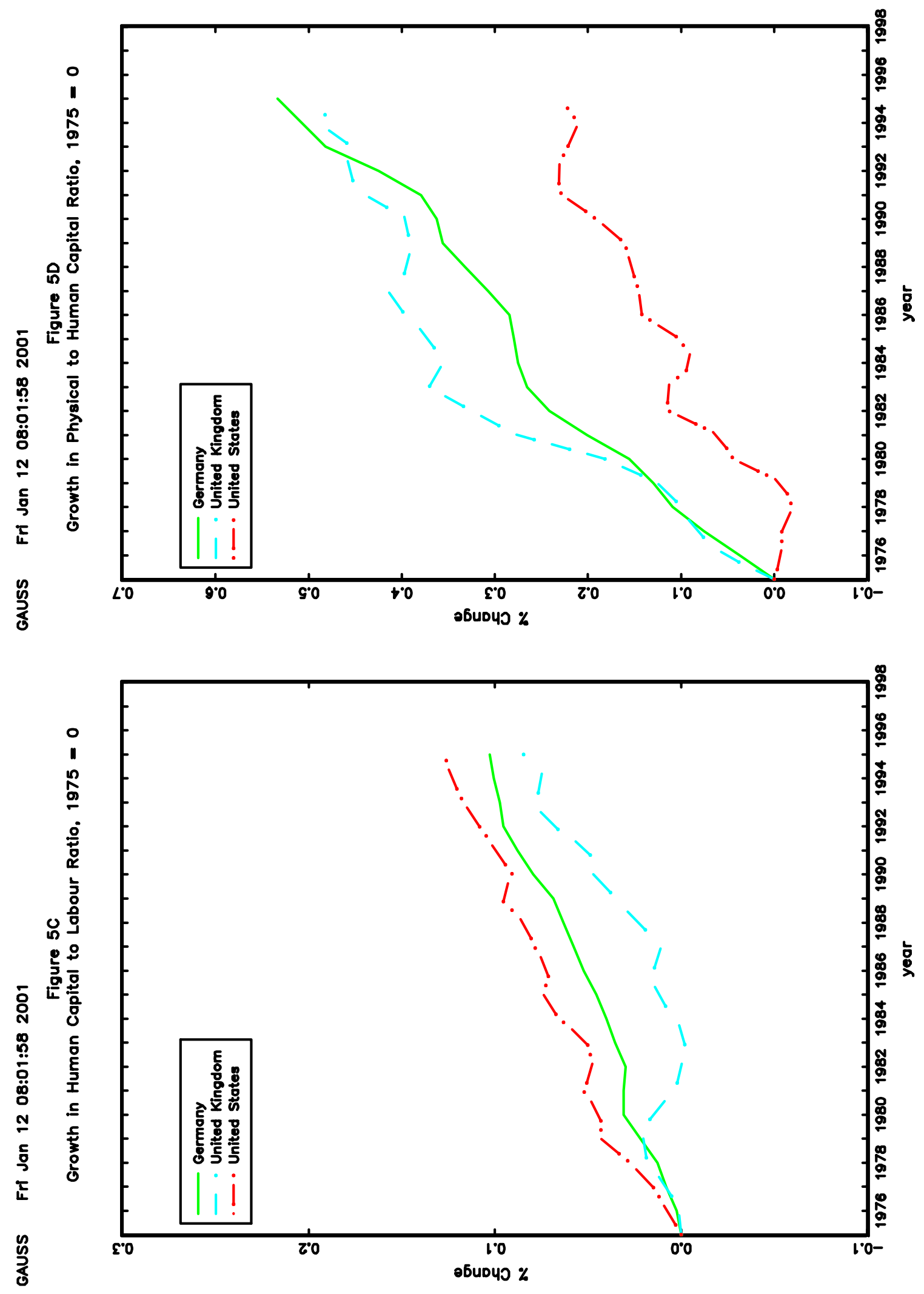